Document downloaded from:

http://hdl.handle.net/10251/144675

This paper must be cited as:

Alonso-Martinez, M.; Adam, JM.; Alvarez-Rabanal, FP.; Del Coz Diaz, JJ. (10-2). Wind turbine tower collapse due to flange failure: FEM and DOE analyses. Engineering Failure Analysis. 104:932-949. https://doi.org/10.1016/j.engfailanal.2019.06.045

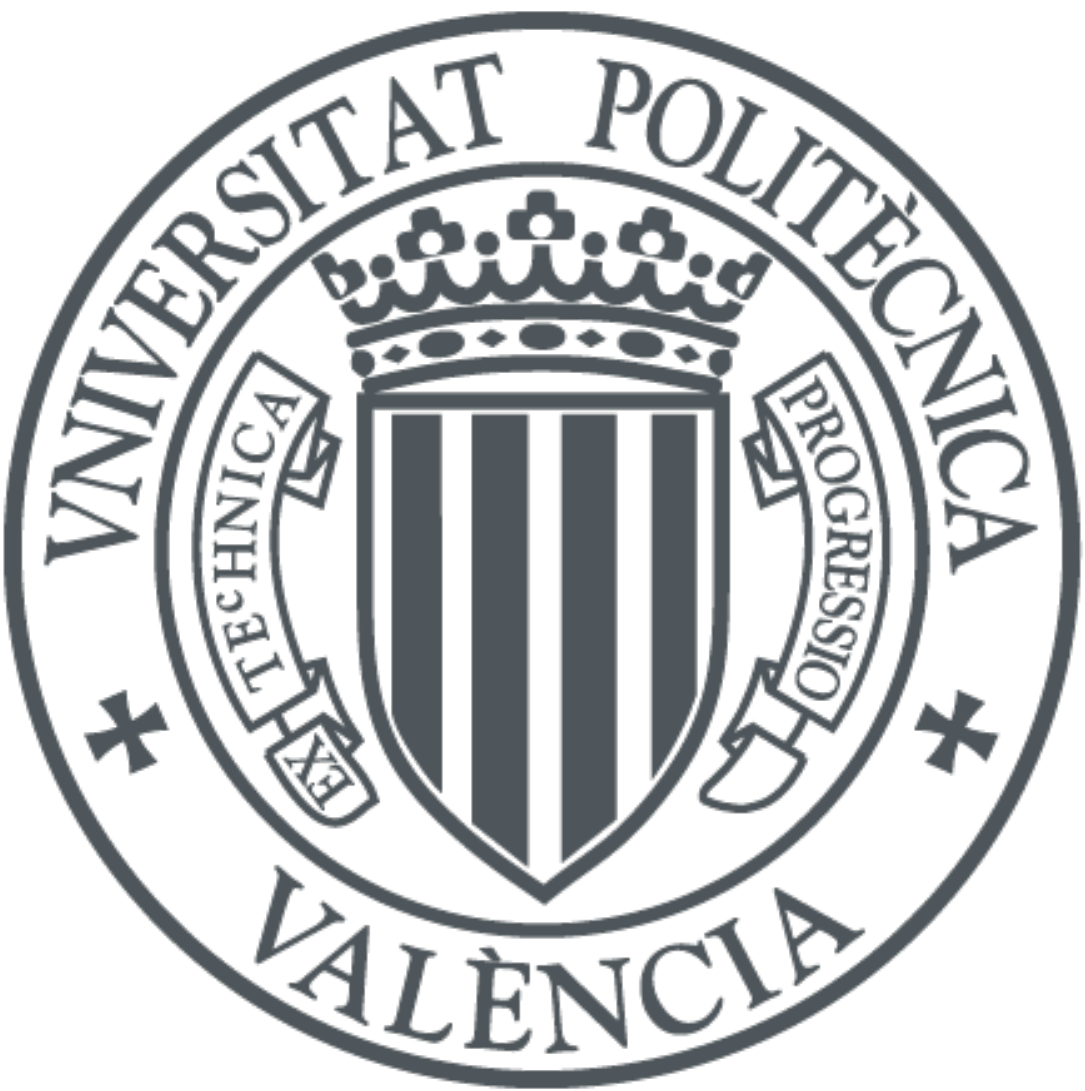

The final publication is available at

https://doi.org/10.1016/j.engfailanal.2019.06.045

Copyright Elsevier

Additional Information 


\title{
Wind turbine tower collapse due to flange failure: FEM and DOE analyses
}

3

4

5

\section{ABSTRACT}

Although a large number of papers have been published to date on failures in wind turbines, most of them have focused on blade failures and less attention has been paid to the tower failures. This paper analyses the causes that led to the failure of one element that finally caused the whole tower to collapse. A diagnosis of the cause of the failure was carried out after an initial on-site inspection, when the origin of the failure appeared to be in the flange that joined the tower to its base. An experimental program was carried out to analyze the characteristics of the steel in the area nearest to the flange. A non-linear simulation was then performed by the finite element method (FEM) of the flange area where the failure had occurred, including the bolts, their prestressing forces and the contact between the joined surfaces. In order to study the influence of different variables on the flange's structural response, a method based on the Design of Experiments (DOE) was used on the FEM model. Finally, the main lessons learnt from the experience are given with the aim of contributing to improving the design and construction of wind turbine towers.

\author{
Mar Alonso-Martinez a ${ }^{\text {a }}$, José M. Adam ${ }^{\mathrm{b}}$, Felipe P. Alvarez-Rabanal ${ }^{\mathrm{a}}$, \\ Juan J. del Coz Díaz \\ aDepartment of Construction, EPSIII, University of Oviedo, 33204 Gijón, Spain \\ ' ICITECH, Universitat Politècnica de València, Camino de Vera s/n, 46022 Valencia, Spain
}


The development of alternative sources of energy to fossil fuels has made steady progress since the world energy crisis of the seventies and has expanded with the search for clean forms of renewable energy, of which wind power has played an important role, due to its technology, infrastructure and relatively low cost [1].

Wind power is produced by using the action of the wind on an electric generator known as a wind turbine, whose main parts are the rotor blades moved by the wind, joined to an electric generator incorporating specific system management components for generating and transmitting electricity. All the equipment is supported by a tower held in place on its foundations.

In order to increase the efficiency of wind turbines, the size of these towers has continually grown throughout the years $[1,2]$. The 2-3 MW wind turbines that used to dominate the market have been replaced by those of 3-5 MW [1].

At the present time most of the towers are constructed of steel tubes. The first models were built with steel lattices, but as they grew in size this system was considered inappropriate and they were replaced by the steel tubes now in use. These tower tubes are usually manufactured in two or three segments that are joined together on site, either by bolts and flanges or by welding.

The ever-increasing size of the wind turbines have meant that static calculation methods, which assumed a constant wind speed, have been replaced by dynamic simulation software that allows the aero-elastic response of the complete wind turbine to be simulated with variable dynamic loads, including the tower, the drivetrain, the rotor blades and the control system [1].

The complexity of the wind turbine structures and its components has also been the cause of a number of serious accidents. These wind turbines are generally, though not always; in the form of wind farms situated in open spaces far from residential areas. When they are close to infrastructures and built-up areas they may be a serious risk.

Wind turbine failure is often due to the failure of rotor blades or of the steel tower [3, 4]. Many papers have been published on blade failures containing simulation by numerical methods or experimental tests [4-11]. When the tower collapses it can cause serious damage to property entailing financial losses and may be due to diverse causes, one of which is the buckling of the steel tower, as pointed out in Lee \& Bang [12]. Other possible causes include steel fatigue due to vibration or being shaken by the wind, failure or incorrect placement of the bolts in the base of the structure or in the joints between the different steel tube sections, as described in Chou \& $\mathrm{Tu}[13]$.

The investigation and study of real failures can provide important information for the improvement of the design of structural elements based on new theories, concepts, construction details, monitoring, etc. [14-16]. The reason for publishing the present study was because only a few papers have been published on the particular case of wind turbine towers. The paper is organized as follows: firstly, the main characteristics of a wind turbine are given, followed by the description of the collapse of one of these structures due to the failure of the tower. The causes of the failure were determined by: visual inspection, laboratory tests, a Finite Element Method (FEM) simulation of the zone in which the failure occurred, and a Design of Experiments (DOE) to assess the influence of the different parameters involved in the 
risk of structural collapse. In the final section, the lessons learnt from the study are given with the aim of contributing to improving the design and construction of wind turbine towers.

\section{Description of the wind turbine}

The Abuela de Santa Ana onshore wind farm is located near the town of Pozo Llorente in the province of Albacete (Spain). It consists of $25 \mathrm{GE}$ Energy 1.5sle Model 1.5KW wind turbines, the diameter of the rotor is $77 \mathrm{~m}$ and the height of the tower varies between $61.4 \mathrm{~m}$ and $85 \mathrm{~m}$. It is operational at the present time under the control of the ACS Company at a nominal power of $37.500 \mathrm{~kW}$. Its geographic coordinates are $39^{\circ} 4^{\prime} 36.5^{\prime \prime}$ latitude and $-1^{\circ} 30^{\prime} 23.5^{\prime \prime}$ longitude. A view of the wind farm with a close-up of a tower can be seen in Fig. 1 .

\section{Fig. 1. General view of the Abuela de Santa Ana wind farm and one of the towers}

The turbine towers are composed of different steel tubes and the flange is fixed to the lower tube and is embedded in the foundations (see Fig.2). The tower tubes are bolted together and are required to maintain the necessary stiffness to support the turbine nacelles fixed to the top of the tower.

The flange is placed in the lower part of the tower. The flange is a steel tube $1.67 \mathrm{~m}$ long and $4.3 \mathrm{~m}$ diameter. It consists of the following components (see Fig. 2):

- Lower T-flange to transmit loads to the foundations.

- Upper flange fixed to the next tower section by M36a bolts.

Fig. 2. Details of the tower/foundation connection. a) Detail of lower flange and foundation; b) Detail of flange and bolts. Source: [17]

The lower tube is totally embedded in concrete except for the upper $0.2 \mathrm{~m}$ which are available for bolting to the tower shell. Due to its failure, the flange in one of the towers between the foundations and the structure was the object of the present study.

\section{Collapse of the turbine tower}

In October 2008, two months after being out into operation, one of the Abuela de Santa Ana wind turbine towers collapsed due to a catastrophic failure in the lower flange fixed to the foundations. An on-site inspection of the damage was made the following day.

Firstly, the joint between the tower and the nacelle was seen to be in good condition with no evidence of damage at this location having caused the failure. Secondly, the steel tube was buckled, as can be seen in Fig. 3. Thirdly, the blades were seen to have damaged the steel tubes during the fall. After the inspection, the most probable cause was therefore identified as the failure of the base of the tower, which was made the focus of future tests to find the definite cause of the collapse.

Fig. 3. View of the tower the day after collapsing

After the base had been analyzed in greater detail, the failure was located in the lower flange. This component had been built from a bar of rectangular cross-section, curved and welded S-355-J2 steel 
according to the UNE-EN-10025-3:2006 code [18] and in the zone of the failure had been welded to a steel tube.

Fig. 4. View of the section in which the failure began

The damaged zone (See Fig.4) showed signs of corrosion, which would later be analyzed to identify the type of failure and its causes. This section was covered with a plastic sheet in order to keep these zones intact and avoid any deterioration in the material due to the weather subsequent to the collapse that could possibly lead to errors in the conclusions of the analysis.

The preliminary visual study identified a sector of approximately $3 \mathrm{~m}$. that had been badly affected by black, blue and brown colored oxidation, in contrast to the rest of the section in which the surface was seen to be clean (Fig.4).

\section{Analysis of the collapse}

\subsection{Visual inspection of the broken section}

A scheme of the flange studied in this work can be seen in Fig. 5. The flange had been positioned in order of the drill holes numbered from 1 to 138 , number 1 being at the centre of the lower tower access door. The broken section to be studied in detail was joined to the flange whose scheme is shown in Fig. 5 .

\section{Fig. 5. Detail of the flange and position of the cracks}

The broken section was found to have started and propagated in the base of the flange neck (see Fig.6a). In photographs taken days after the collapse, various cracks were located in the flange cross-section, as can be seen in Fig. 6:

- The initial crack was located between drill holes 100 and 130 (see Fig.6c)

- Between drill holes 109 and 123 black and blue rust stains were observed (see Fig.6b). These stains were visible in the on-site inspection and were thus assumed to exist before the collapse of the structure.

In view of the above, the start of the break was considered to date approximately from the time when the tower had been constructed, due to the oxidation in the broken section.

The failure mode observed in the flange provided information to make a preliminary diagnosis of the collapse that would later be verified by experimental tests and numerical analysis. This diagnosis identified the initial crack that did not spread any further and that could have been due to the forces induced by the bolt pretension or also possibly by a crack in the flange due to an impact during its installation in the tower.

Fig. 6. Detail of the damaged flange section. a) Side view; b) Top view; c) Detail of crack start point

The detailed analysis of the oxides found in the damaged section included a large amount of blue oxides organized into bands or groups of points (see Fig. 6c and Fig. 7) characteristic of the so-called blue 
brittleness or brittle martensite. The former is often found in most steels and is due to the transformation of austenite into cementite at the grain boundaries when the material is subjected to temperatures around $300^{\circ} \mathrm{C}$. The decomposition of the austenite seriously reduces the toughness of the material. This type of brittleness is accentuated by the segregation of impurities at the grain boundary, which promotes the intergranular breaks typical of brittle fractures [19] and [20]. Some authors have observed that blue brittleness when combined with corrosion cracks can cause disastrous failures in steel components [2123].

\section{Fig. 7. Detail of the broken flange section}

From the initial analysis based on measurements taken on site and a visual inspection, it was considered that the failed flange could have been the determining factor in the collapse of the tower. Details of the flange manufacturing process are given in the following section.

\subsection{Flange manufacturing process}

The flange dimensions are as follows: $4.3 \mathrm{~m}$. external diameter, $0.107 \mathrm{~m}$. maximum thickness, and 0.15 $\mathrm{m}$. in width, with 138 drill holes of $0.039 \mathrm{~m}$. in diameter. The section geometry and tolerances are given in Fig. 8.

Fig. 8. Geometry of flange section

The flange was made from a rectangular section S-355-J2 steel bar (dimensions: $4.3 \times 0.17 \times 0.12$ mxmxm) according to UNE-EN 10025-3:2006 [18]. The first treatment is the normalizing, after which it is cold formed and welded. The next step is the thermal treatment to eliminate any residual stresses after cold-forming. In the final stage it is machined into the required shape within the necessary tolerances. Mechanical properties of this material are well known. Quality tests were done by the steel manufacturer to ensure the material properties of the project requirements.

\section{Experimental tests}

In view of the type of failure discovered in the flange, close to the welded zone, the material was analyzed to obtain the fracture toughness parameters. Three Charpy specimens were extracted from the flange between drill holes 112 and 114, as shown in Fig. 9 [24].

Fig. 9. Detail of the specimen extraction zone. Source [24]

The tests gave mean toughness values of 13 Joules for specimen W (working direction), i.e. in the direction of the tower generatrix (direction of tensile stresses in the flange when the structure is subjected to bending forces), and 10 joules for specimen $\mathrm{M}$ (manufacturing direction), i.e. longitudinal direction of laminated bar from which the flange is formed, as shown in Table 1.

Table 1. Experimental Results 


\begin{tabular}{lccccc}
\hline & Sy (MPa) & $\mathrm{Su}(\mathrm{MPa})$ & $\mathrm{A}(\%)$ & $\begin{array}{c}\mathrm{Kv}\left(+13^{\circ} \mathrm{C}\right) \\
(\mathrm{J})\end{array}$ & $\mathrm{Kv}\left(-20^{\circ} \mathrm{C}\right)(\mathrm{J})$ \\
\hline Flange W $\left(^{*}\right)$ & 422 & 557 & 24 & 62 & 13 \\
Flange M (**) & 383 & 536 & 28 & --- & 10 \\
S355 J2 & $>295$ & $450-600$ & $>18$ & --- & $>27$ \\
\hline
\end{tabular}

(*) W: Working direction

(**) M: Manufacturing direction

Reference values obtained for S355J2 grade with 105 mm width from UNE-EN 10025-2 [25].

Yield strength (Sy), Tensile Strenght (Su), Deformation (A), Toughness (Kv)

Since the value was below the $27 \mathrm{~J}$ given in the EN10025-3 Code [18], it was therefore concluded that the fracture toughness of the material was unsatisfactory in all directions. In view of these results, a serious weakness was identified in the material that could have been responsible for unforeseeable failures in the behavior of the structure. The experimental results show that the material does not possess the properties required by the current code and this anomaly could have caused the abnormal behavior of the structure that had not been considered in its design.

\section{Finite element modelling}

In the present work, a numerical model based on Finite Element Method studied the behavior of the

188 flange in order to analyze the cause of the collapse. The procedure followed in this stage consisting of 189 a detailed geometrical model of a sector of the flange, taking advantage of its symmetry. The upper and lower steel tubes were included, as were the zones affected by welding and the bolts.

FEM makes it possible to calculate strains and stresses and the possible failure modes under a range of stresses and working conditions [26]. Ansys-Workbench R16.1 Academic software [27] and [28] was used for this study.

194 The analyses were supplemented by a design of experiments (DOE) study (see Section 7) in which the influence of the different input variables was assessed to identify the response of the flange under different conditions.

\subsection{Material properties and geometry}

199 The materials were modelled considering the steel's elastic properties with linear behavior until 200 yielding. The defined material was steel with a modulus of elasticity of $200 \mathrm{GPa}$ and a Poisson's 201 Coefficient of 0.3 , yield strength of $250 \mathrm{MPa}$ and ultimate tensile strength of $460 \mathrm{MPa}$. These properties have been taken from the manufacturer datasheet. 
The geometrical model studied consisted of the lower flange, the upper flange and a bolt joining both parts, to which symmetry conditions were applied in order to reduce the computational cost of the models. Details of the model geometry can be seen in Fig. 10.

\section{Fig. 10. Geometric model: a) Lower flange; b) Upper flange and bolt; c) Complete} (symmetry) model.

\subsection{Finite elements used and contact model}

SOLID95 type finite elements were used for the flange and SHELL93 for the steel tube at a distance from the joint (see Fig.11a). These elements are suitable for modelling curved zones and complex geometries, as in the case under study [25-27].

SOLID95 is a 3-D element with 20 nodes and three degrees of freedom able to accurately simulate irregular geometries and structural phenomena such as plasticity, creep and large deformations, among others [29].

SHELL93 is an element defined by 8 nodes and three degrees of freedom in each node (displacement and rotations in three directions of the space) and is suitable for curved plate models such as the steel tube at a distance from the joint in the present study [29].

The mesh size was minimum $0.0013 \mathrm{~m}$ and maximum $0.27 \mathrm{~m}$, with a total of 266.194 nodes and 71.117 elements. As can be seen in Figure 11b, certain zones of the geometry were modelled with a very fine finite elements mesh due to the curves and transitions between the elements.

\section{Fig. 11. Finite elements mesh: a) General view; b) Detail of the mesh in the bolt}

In this case, the average element quality ratio is 0.806 out of 1 . In consequence, numerical results are in good agreement with the expected behavior. For three-dimensional elements, this metric is based on the ratio of the volume to the sum of the square root of the sum of the square of the edge lengths.

The model was completed with the configuration of the contact between elements and the application of boundary conditions, which consisted of frictional contact between the flanges surfaces and bonded contact between the bolt head and the upper flange surfaces and for the nut with the lower flange surfaces (see Fig.12). The friction coefficient considered was 0.1, adopting an Augmented Lagrangian formulation [30].

\section{Fig. 12. Contacts in model}

\subsection{Loads and boundary conditions}

This section provides details of the loads applied to the finite element (FE) model and the boundary conditions considered for the joint as well as the simplification procedure in order to obtain realistic values and structural response from the engineering point of view.

To begin with, use was made of the flange symmetry to simplify the model and represent the actual continuity of the tower shell and flanges. In this way, only a $1 / 138^{\text {th }}$ sector of the flange was simulated and symmetry conditions were applied (see Fig. 13). Secondly, a restriction was applied on the 
$F=\frac{P_{a}}{v}=\frac{C_{p} \cdot P_{d}}{v}$

$P_{a}=C_{p} \cdot P$

$P=\frac{1}{2} \cdot \rho \cdot A \cdot v^{3}$

Where: (C in Fig. 13).

- A pretension load applied on the bolt joining the upper and lower flanges at a value of $519.91 \mathrm{kN}$ (D in Fig. 13).

The force generated by the wind on the blades causes a bending moment at the base of the tower that subjects the joint to tensile and compressive forces. There are several ways to obtain the wind load on the blades [13], [10]. The use of Computer Fluid Dynamics (CFD) is a useful methodology to obtain the wind load on blades including the aeroelastic behavior. Other authors used this methodology in the last years [31]. Furthermore, the influence of the blade material properties on the tower wind load could be taking into account [32]

In the present work, the load is obtained following the standards and guides as follows [33]. This horizontal force is limited by the available power, $P_{a}$. The available power is obtained by applying a correcting ratio to the power generated due to the kinetic energy of the wind, $P$ (see Eq. (1)). The maximum efficient power of a turbine is restricted by the Betz Limit, which is called the "power coefficient", $C_{p}$ [33]. Betz's Law defines this coefficient for any design of wind turbine at 0.59 . Despite the fact that Betz Law establishes the theoretical maximum power efficiency at $59 \%$, other factors such as strength or durability reduce this value to $0.35-0.45$. Usually, for high performance equipment, the Betz limit value considered is 0.4 .

The power generated is determined by the kinetic energy of the wind in accordance with Eq. (2).

$\rho$ : Air density in $\mathrm{kg} / \mathrm{m}^{3}$

$A$ : Area swept by rotor in $\mathrm{m}^{2}$

$v$ : Linear velocity of the wind in $\mathrm{m} / \mathrm{s}$

The horizontal force on the rotor is determined by Eq. (3).

275 Data on the characteristics of the rotor are required for calculating the horizontal force. The 


\begin{tabular}{lc} 
Table $2 . \quad$ Wind turbine information \\
\hline Wind power component & Values \\
\hline Rotor diameter, $D(\mathrm{~m})$ & 77 \\
Swept area, $A\left(\mathrm{~m}^{2}\right)$ & 4656.6 \\
Nacelle weight, $(\mathrm{kg})$ & 50000 \\
Rotor + hub weight $(\mathrm{kg})$ & 31000 \\
Wind Speed, $v(\mathrm{~m} / \mathrm{s})$ & 5.21 \\
\hline
\end{tabular}

The values obtained for the power and for the horizontal force on the rotor are shown in Table 3.

Table 3. Power and load on the wind turbine.

\begin{tabular}{lc} 
Loads & Values \\
\hline Power $(\mathrm{kW})$ & 742.41 \\
Avaliable Power $(\mathrm{kW})$ & 296.96 \\
Wind force $(\mathrm{kN})$ & 46.57 \\
\hline
\end{tabular}

284 The maximum tensile stress on the tower flange is due to two main forces (see Eq. (4)):

285 - The bending moment caused by the horizontal force of the wind on the rotor.

286 - The weight of the turbine unit and the tower, which generate a normal force on the flange.

$287 \quad \sigma_{\max (c)}=\frac{M_{f}}{W_{f}}+\frac{P_{p}}{S}$

288 Where:

$M_{f}$ : Bending moment on the tower flange $(\mathrm{kN} \cdot \mathrm{m})$

$290 W_{f}$ : Bending resistance $\left(\mathrm{m}^{3}\right)$

$291 \quad P_{p}$ : Self-weight $(\mathrm{kN})$

$292 S$ : Cross-section area of the tower $\left(\mathrm{m}^{2}\right)$

293 The bending moment in the tower flange is obtained by multiplying the horizontal force on the rotor by

294 the distance to the base of the tower (Eq. (5)).

$295 \quad M_{f}=F \cdot d \cdot \gamma$

296 Where: 
$298 d$ : Distance to the base of the tower, $80 \mathrm{~m}$.

$\gamma$ : Safety factor, 1.5

300 To calculate the self-weight, the weight of the tower $\left(P_{w-t o w e r}\right)$ and the weight of the turbine unit $\left(P_{w-}\right.$ 301 turbine) comprising the nacelle, rotor and hub must all be taken into consideration (Eq. (6)). Data 302 necessary to obtain $P_{w-t o w e r}$ and $P_{w-t u r b i n e}$ are shown in Table 2.

304 The weight of the tower $\left(P_{\text {w-tower }}\right)$ is $169.67 \mathrm{kN}$, and the weight of the wind turbine $\left(P_{w-t u r b i n e}\right)$ is $810 \mathrm{kN}$, 305 including the nacelle, rotor and hub[34]. Therefore, the self-weight of the wind turbine $\left(P_{p}\right)$ is 979.67 $306 \mathrm{kN}$.

307 By using these data, the maximum stress on the flange can be expressed by Eq. (4), while the minimum 308 stress can be determined by the tensile stress on the flange (Eq. (7)).

$\sigma_{\min (t)}=\frac{M}{W_{f}}-\frac{P_{p}}{S}$

The stress values on the flange are shown in Table 4.

Table 4. Stress values on the flange

\begin{tabular}{|c|c|}
\hline Stress & \\
\hline $\begin{array}{l}\text { Max. Compression Stress } \\
\sigma_{\max (c)}(\mathrm{MPa})\end{array}$ & 16.64 \\
\hline 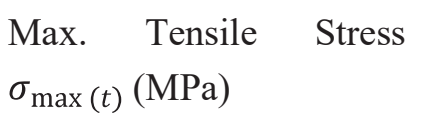 & 9.38 \\
\hline $\begin{array}{l}\text { Max. Compressive load } \\
(\mathrm{kN})\end{array}$ & $(-) 32.57$ \\
\hline Tensile Load $(\mathrm{kN})$ & $(+) 18.37$ \\
\hline
\end{tabular}

313 Based on the results obtained, the normal load applied to the flange was varied between $15 \mathrm{kN}$ of maximum tensile load and $40 \mathrm{kN}$ of maximum compressive load for the study of all the states of intermediate loads between the maximum load (compressive) and the minimum load (tensile).

\section{Fig. 13. Boundary conditions used on a section of the flange}

317 The computational calculation was performed by means of the Newton-Raphson iterative method, 318 based firstly on the pretension analysis of the bolt with a subsequent application of all the loads required 319 by the flange. The pretension load is modelled using a set of pretension elements (element type PRETS179), [28]. This element has one translation degree of freedom, which is the pretension direction. The surfaces connected by the pretension elements must be matched using coincident nodes in both meshes to obtain accurate results. A total of 8 sub-steps and 17 iterations were necessary before model convergence was achieved. 


\subsection{Analysis of the results}

The results obtained from the numerical simulations provided interesting information for an exhaustive analysis of the tower failure. On analyzing the stresses in the joint it was seen that the prestressing of the bolts, before considering the other loads, exerts high forces on the joint, as can be seen in Fig. 14a, since the flange steel's yield strength is exceeded. As a result, the flange is already in a highly stressed state even before the other loads on the structure are taken into account.

After applying loads on the structure, the numerical model showed a high concentration of stresses on the flange neck that coincided with the point of the failure observed in the visual inspection. After analyzing the results of the numerical model, it is shown that the Maximum Von-Mises stress exceeded the material's yield strength (see Fig.14b).

Fig. 14 gives the most important results of the Von Mises stress distribution in the flange. Fig. 14a shows the stress state of the joint when subjected to bolt pretension only. Fig. 14b includes the stress state of the flange when subjected to all the loads.

Fig. 14. FEM model results, equivalent Von-Mises stress. a) applying bolt pretension only (in $M P a$ ); b) for all applied loads (in $M P a$ )

\section{Design of experiments (DOE)}

\subsection{General information}

Design of Experiments (DOE) is a technique used to identify the influence of input parameters on output parameters, as well as to optimize the analysis results. This technique is widely used in engineering to obtain results from a range of input parameters using a minimum of input sampling points. Response surface provide intermediate results. The accuracy of the response surface depends on the type of DOE and the number of cases studied, [35].

In this work, a DOE, type Central Composite Design (CCD), was used to study the influence of certain conditions on the level of stresses in each part of the flange section. This method was used by the authors in previous work on the analysis of structural failures and to optimize new designs [32-34].

In this case, the focus was on the flange bolt pretension, the coefficient of friction in the flange contact, and the vertical force on the flange, which could affect the structural integrity of the joint. The output parameters studied were the maximum stress on the[35] joint and the maximum Von Mises stress in the analysis. Table 5 gives the maximum values adopted for the input variables and their initial values.

Table 5. Values of parameters in the DOE

\begin{tabular}{lccc}
\hline & Minimum Value & Initial Value & Maximum Value \\
\hline Frictional Coefficient & 0.1 & 0.1 & 0.3 \\
Bolt preload (kN) & 100 & 520 & 571 \\
Force (Y axis) (kN) & -40 & 32.5 & 15 \\
\hline
\end{tabular}


The analysis identified the individual critical stress values for each element under different load states. The results obtained allowed us to identify the most important critical points in the joint, the influence of the input variables on each one, and the permitted load limits to keep the structure in a state of stress within the material's admissible limits.

The DOE analysis can identify the cause of the fracture of the joint, the load limits that would cause the collapse of the structure and the different load combinations that would overload the joint and cause it to have brittle behavior.

\subsection{Analysis of the results}

The maximum stress values were the most important results obtained from the numerical analysis of the joint, including the contact stress between both flanges and the individual stress level of both the upper and lower flanges.

In regard to the flange contact pressure (see Fig.15a), the maximum value obtained was in the central axis of the surface and reached a value of $62.8 \mathrm{MPa}$. The maximum Von Mises stress values in upper and lower flanges were very high (see Figs. $15 \mathrm{~b}$ and $15 \mathrm{c}$ ).

Fig. 15. Results of the FE model and DOE analysis: a) Contact stress between upper and lower flanges (in Pa); b) Von Mises stress in upper flange (in Pa); c) Von Mises stress in lower flange (in $\mathrm{Pa}$ )

The DOE results also contributed to the diagnosis of the collapse of the structure by identifying the the most influential variables of the limit stress state of the joint. In the sensitivity analysis shown in Fig. 16 , it can be seen that the most influential parameter is the pretension stress applied to the bolt, followed by the vertical component of the load applied to the steel tube, and lastly the coefficient of friction between the contact surfaces of the flanges.

\section{Fig. 16. Sensitivity analysis}

Fig. 17 shows the response surface that reflects the variation in maximum Von Mises stress in the different parts of the upper and lower flanges. In both cases the maximum Von Mises stress considered was in the part nearest to the steel tube, since, as was seen previously, this is the zone of the flange with the highest concentration of stresses.

The response surfaces obtained from the DOE had maximum values very similar to the upper and lower parts of the flange. It was also seen that the bolt pretension load had a greater influence than the vertical load on the steel tube in the maximum von Mises stress value.

Fig. 17. DOE analysis: External part of the flange (upper and lower part. a) Bolt pretension vs Force Y in upper part of the flange; b) Bolt pretension vs Force Y in lower part of the flange

Fig. 18a shows the influence of the bolt pretension load and of the coefficient of friction with respect to the pressure in the contact between the flanges. It can be seen that the most influential parameter is the pretension load. Figure $18 \mathrm{~b}$ shows the influence of the vertical load on the pressure value; it can be seen that the greatest influence is due to the vertical load applied to the steel tube.

Fig. 18. DOE analysis: maximum pressure in contact between the flanges: a) Contact friction vs Bolt pretension; b) Contact friction vs Force Y. 


\section{Diagnosis}

401

402

403

404

405

406

407

408

409

410

411

412

413

414

415

416

417

418

419

420

421

422

423

424

425

426

427

428

429

430

431

432

433

434

435

436

In the visual inspection carried out on site it was determined that the failure had occurred in two phases in a brief interval of time:

1) The initial failure appeared to be caused by force that disappeared after the crack started (a case of imposed deformation and/or a temporary force derived from an undue event). After this study, it was considered that the failure occurred during the building of the turbine tower, when the pretension was applied to the bolts.

2) The second failure occurred when the tower was in service and the resistant section became weakened because of the initial fracture and progressed until the tower collapsed.

The presence of blue oxides in the fracture zone indicated the possibility of a defect in the manufacture of the element. To verify this, experimental tests were carried out on the toughness of the steel used in the tower and showed that the steel did not meet the requirements of the resilience test. The steel was shown to have very low toughness and was not suitable for use in the structure.

FEM numerical simulations and DOE were used in the present study to analyze the collapse of the wind turbine tower. The results obtained showed that the pretension of the bolts, before considering the remaining forces, exerted considerable stresses on the joint (Fig.14a) that reached the yield strength of the steel in the flange. This high concentration of stresses occurred precisely at the fracture point in the flange neck observed in the visual inspection. The sensitivity analysis by DOE (Fig.16) also showed that the most influential parameter in regard to the von Mises stresses in the joint was the preload stress applied to the bolts. Finally, the response surfaces obtained from the DOE analysis showed that the bolt pretension load had a clearly greater influence than the vertical load and the coefficient of friction in the value of the maximum von Mises stress throughout the range of loads applied to the flange.

Therefore, based on the visual inspection, the laboratory tests carried out and the numerical technique employed (FEM models, sensitivity analysis, response surfaces and the DOE-based method) it can be stated that the collapse of the tower was due to defective material combined with errors in the design of the flange. Both issues make the stress due to the bolt pretension combined with the residual welding stresses are higher than the strength and toughness of the flange material.

\section{Conclusions and lessons learned}

This paper analyze the collapse of a wind turbine tower. The causes of the failure were determined by a visual inspection, laboratory tests, FEM simulations and a subsequent DOE analysis. The main lessons learned can be summed up as follows:

1. On-site inspection of the collapsed structure is essential, together with the immediate isolation of the fractured section to avoid any changes due to oxidation or other agencies.

2. The observation of the fractured section and detailed photographs of all sectors to show differences in colour or appearance can also contribute to clarifying the causes of a collapse. 
3. The experimental analysis of all material properties such as resistance or toughness is fundamental to establish the possible causes of the failure.

4. The creation of detailed FEM models to study the load distribution in the broken section enable the analysis of possible causes of the failure.

5. Applying the DOE technique in the study provides information on the structural behaviour when the physical properties or the loads have wide range of variations and is a fundamental tool for identifying the basic variables involved in the phenomenon.

In the present case, the failure could have been avoided if the material used in the flange had been subjected to the appropriate quality control (toughness test). It could also have been avoided had the flange been better designed to remove the maximum service stress away from the zone affected by the welding, e.g. with a larger chord radius and longer neck.

\section{Acknowledgements}

The authors are grateful for the collaboration of the GICONSIME Research Group at the University of Oviedo and COMONOR Ltd for providing useful information on the tower failure. The authors also acknowledge the partial funding from FEDER funds under the Research Project FC-15-GRUPIN14004. Finally, the authors would also like to thank Swanson Analysis Inc. for the use of ANSYS University Research programs as well as the Workbench simulation environment.

\section{References}

[1] C.C. Chia, J.-R. Lee, Hyung-Joon Bang, Structural health monitoring for a wind turbine system: a review of damage detection methods, Meas. Sci. Technol. 19 (2008) 122001. doi:10.1088/0957-0233/19/12/122001.

[2] Y. Lin, L. Tu, H. Liu, W. Li, Fault analysis of wind turbines in China, Renew. Sustain. Energy Rev. 55 (2016) 482-490. doi:10.1016/j.rser.2015.10.149.

[3] Caithness Windfarm Information Forum (CWIF), Summ. Wind Turbine Accid. Data to 30 Sept. 2014. (n.d.). http://www.caithnesswindfarms.co.uk/ (accessed August 9, 2016).

[4] F.P.G. Marquez, J.M.P. Perez, A.P. Marugan, M. Papaelias, Identification of critical components of wind turbines using FTA over the time, Renew. Energy. 87 (2016) 869-883. doi:10.1016/j.renene.2015.09.038.

[5] L.C.T. Overgaard, E. Lund, Structural collapse of a wind turbine blade. Part B: Progressive interlaminar failure models, Compos. Part A Appl. Sci. Manuf. 41 (2010) 271-283. doi:10.1016/j.compositesa.2009.10.012.

[6] M.M. Shokrieh, R. Rafiee, Simulation of fatigue failure in a full composite wind turbine blade, Compos. Struct. 74 (2006) 332-342. doi:10.1016/j.compstruct.2005.04.027.

[7] C. Kong, J. Bang, Y. Sugiyama, Structural investigation of composite wind turbine blade considering various load cases and fatigue life, Energy. 30 (2005) 2101-2114. doi:10.1016/j.energy.2004.08.016. 
[8] F.M. Jensen, B.G. Falzon, J. Ankersen, H. Stang, Structural testing and numerical simulation of a $34 \mathrm{~m}$ composite wind turbine blade, Compos. Struct. 76 (2006) 52-61. doi:10.1016/j.compstruct.2006.06.008.

[9] L.C.T. Overgaard, E. Lund, O.T. Thomsen, Structural collapse of a wind turbine blade. Part A: Static test and equivalent single layered models, Compos. Part A Appl. Sci. Manuf. 41 (2010) 257-270. doi:10.1016/j.compositesa.2009.10.011.

[10] C.P. Chen, T.Y. Kam, Failure Analysis of Small Composite Sandwich Turbine Blade Subjected to Extreme Wind Load, Procedia Eng. 14 (2011) 1973-1981. doi:10.1016/j.proeng.2011.07.248.

[11] X. Chen, W. Zhao, X.L. Zhao, J.Z. Xu, Preliminary failure investigation of a 52.3m glass/epoxy composite wind turbine blade, Eng. Fail. Anal. 44 (2014) 345-350. doi:10.1016/j.engfailanal.2014.05.024.

[12] K.-S. Lee, H.-J. Bang, A study on the prediction of lateral buckling load for wind turbine tower structures, Int. J. Precis. Eng. Manuf. 13 (2012) 1829-1836. doi:10.1007/s12541-012-0240-y.

[13] J.-S. Chou, W.-T. Tu, Failure analysis and risk management of a collapsed large wind turbine tower, Eng. Fail. Anal. 18 (2011) 295-313. doi:10.1016/j.engfailanal.2010.09.008.

[14] J.M. Adam, F.J. Pallares, Special Issue Learning from Structural failures, Eng. Struct. 32 (2010) 1791. doi:10.1016/j.engstruct.2010.04.026.

[15] N. Delatte, Failure literacy in structural engineering, Eng. Struct. 32 (2010) 1952-1954. doi:10.1016/j.engstruct.2009.12.015.

[16] M. Currie, M. Saafi, C. Tachtatzis, F. Quail, Structural integrity monitoring of onshore wind turbine concrete foundations, Renew. Energy. 83 (2015) 1131-1138. doi:10.1016/j.renene.2015.05.006.

[17] Installing and Assembling Wind Turbine Towers, (n.d.). http://drømstørre.dk/wpcontent/wind/miller/windpower web/en/tour/manu/towrassy.htm (accessed August 9, 2016).

[18] UNE-EN 10025-3. Hot rolled products of structural steels. Part 3: Technical delivery conditions for normalized rolled weldable fine grain structural steels, 2006.

[19] O.F. Higuera Cobos, J.F. Arroyave Londoño, C. Jaramillo I., Estudio de la fragilidad en azul del acero de ultra-alta resistencia assab supra 709., Sci. Tech. ISSN 0122-1701, Vol. 3, №. 40, 2008, Págs. 60-64. 3 (2008) 60-64.

[20] N. Pazos Peinado, Tecnología de los Metales y Procesos de Manufactura, Universida, Caracas, 2006.

[21] W.Y. Chu, Y.B. Wang, L.J. Qiao, Interaction between blue brittleness and stress corrosion cracking, J. Nucl. Mater. 280 (2000) 250-254. doi:10.1016/S0022-3115(00)00065-9.

[22] M.C.S.W. Xue, The blue brittleness of $1 \mathrm{Cr} 17 \mathrm{Ni} 2$ steel submarine motor shaft, Mater. Lett. 57 (2002) 369-373. doi:10.1016/S0167-577X(02)00794-2.

[23] H. Cui, W. Wang, A. Li, M. Li, S. Xu, H. Liu, Failure analysis of the brittle fracture of a thickwalled 20 steel pipe in an ammonia synthesis unit, Eng. Fail. Anal. 17 (2010) 1359-1376. doi:10.1016/j.engfailanal.2010.04.002.

[24] UNE 7475-1:1992. Metallic materials Charpy impact test. Part 1: Test method, 1992.

[25] UNE-EN 10025-2:2006. Hot rolled products of structural steels - Part 2: Technical delivery conditions for non-alloy structural steels., 2006. 
[26] O.C. Zeinkiewick, C. Y.K., The finite element method in structural and continuum mechanics, McGraw Hill, London, 1967.

[27] M. E., G. I., The Finite Element Method and Applications in Engineering using ANSYS, Springer, Berlin, 2005.

[28] S. Moaveni, Finite Element Analysi: Theory and Application with ANSYS, Prentice-Hall, New York, 2007.

[29] S.A. System, ANSYS. User's manual: procedures, commands and elements., Canonsburg, PA, 2005.

[30] J.C. Simo, T.A. Laursen, An augmented lagrangian treatment of contact problems involving friction, Comput. Struct. 42 (1992) 97-116. doi:10.1016/0045-7949(92)90540-G.

[31] R. Rafiee, M. Tahani, M. Moradi, Simulation of aeroelastic behavior in a composite wind turbine blade, J. Wind Eng. Ind. Aerodyn. 151 (2016) 60-69. doi:10.1016/J.JWEIA.2016.01.010.

[32] R. Rafiee, M. Moradi, M. Khanpour, The influence of material properties on the aeroelastic behavior of a composite wind turbine blade, J. Renew. Sustain. Energy. 8 (2016) 063305. doi:10.1063/1.4968600.

[33] The Royal Academy of Engineering, Wind Turbine Power Calculations RWE npower renewables Mechanical and Electrical Engineering, R. Acad. Eng. (n.d.).

[34] thewindpower.net, (n.d.). http://www.thewindpower.net/turbine_es_57_ge-energy_1.5sle.php (accessed December 6, 2016).

[35] D. c. Montgomery, Design and Analysis of Experiments, 5th ed., 2001.

[36] J.J. del Coz Díaz, P.J. García Nieto, A. Lozano Martínez-Luengas, J.L. Suárez Sierra, A study of the collapse of a WWII communications antenna using numerical simulations based on design of experiments by FEM, Eng. Struct. 32 (2010) 1792-1800. doi:10.1016/j.engstruct.2009.09.011.

[37] J.J. del Coz Díaz, F.P. Álvarez Rabanal, P.J. García Nieto, J. Roces-García, A. AlonsoEstébanez, Nonlinear buckling and failure analysis of a self-weighted metallic roof with and without skylights by FEM, Eng. Fail. Anal. 26 (2012) 65-80. doi:10.1016/j.engfailanal.2012.07.019.

[38] J. José del Coz Díaz, J.M. Adam, A.L. Martínez-Luengas, F.P. Alvarez Rabanal, Collapse of a Masonry Wall in an Industrial Building: Diagnosis by Numerical Modeling, J. Perform. Constr. Facil. 27 (2013) 65-76. doi:10.1061/(ASCE)CF.1943-5509.0000310. 


\section{Highlights:}

- Wind tower collapse due to the failure of a flange is analyzed

- Analysis of the material properties is needed to identify the causes of the failure

- Finite Element model shows the load distribution in the broken section

- The most influential parameters are obtained applying Design of Experiments (DOE) 







\title{
Wind turbine tower collapse due to flange failure: FEM and DOE analyses
}

3

4

5

\section{ABSTRACT}

Although a large number of papers have been published to date on failures in wind turbines, most of them have focused on blade failures and less attention has been paid to the tower failures. This paper analyses the causes that led to the failure of one element that finally caused the whole tower to collapse. A diagnosis of the cause of the failure was carried out after an initial on-site inspection, when the origin of the failure appeared to be in the flange that joined the tower to its base. An experimental program was carried out to analyze the characteristics of the steel in the area nearest to the flange. A non-linear simulation was then performed by the finite element method (FEM) of the flange area where the failure had occurred, including the bolts, their prestressing forces and the contact between the joined surfaces. In order to study the influence of different variables on the flange's structural response, a method based on the Design of Experiments (DOE) was used on the FEM model. Finally, the main lessons learnt from the experience are given with the aim of contributing to improving the design and construction of wind turbine towers.

\author{
Mar Alonso-Martinez a ${ }^{\text {a }}$, José M. Adam ${ }^{\mathrm{b}}$, Felipe P. Alvarez-Rabanal ${ }^{\mathrm{a}}$, \\ Juan J. del Coz Díaz \\ aDepartment of Construction, EPSIII, University of Oviedo, 33204 Gijón, Spain \\ ' ICITECH, Universitat Politècnica de València, Camino de Vera s/n, 46022 Valencia, Spain
}


The development of alternative sources of energy to fossil fuels has made steady progress since the world energy crisis of the seventies and has expanded with the search for clean forms of renewable energy, of which wind power has played an important role, due to its technology, infrastructure and relatively low cost [1].

Wind power is produced by using the action of the wind on an electric generator known as a wind turbine, whose main parts are the rotor blades moved by the wind, joined to an electric generator incorporating specific system management components for generating and transmitting electricity. All the equipment is supported by a tower held in place on its foundations.

In order to increase the efficiency of wind turbines, the size of these towers has continually grown throughout the years $[1,2]$. The 2-3 MW wind turbines that used to dominate the market have been replaced by those of 3-5 MW [1].

At the present time most of the towers are constructed of steel tubes. The first models were built with steel lattices, but as they grew in size this system was considered inappropriate and they were replaced by the steel tubes now in use. These tower tubes are usually manufactured in two or three segments that are joined together on site, either by bolts and flanges or by welding.

The ever-increasing size of the wind turbines have meant that static calculation methods, which assumed a constant wind speed, have been replaced by dynamic simulation software that allows the aero-elastic response of the complete wind turbine to be simulated with variable dynamic loads, including the tower, the drivetrain, the rotor blades and the control system [1].

The complexity of the wind turbine structures and its components has also been the cause of a number of serious accidents. These wind turbines are generally, though not always; in the form of wind farms situated in open spaces far from residential areas. When they are close to infrastructures and built-up areas they may be a serious risk.

Wind turbine failure is often due to the failure of rotor blades or of the steel tower [3, 4]. Many papers have been published on blade failures containing simulation by numerical methods or experimental tests [4-11]. When the tower collapses it can cause serious damage to property entailing financial losses and may be due to diverse causes, one of which is the buckling of the steel tower, as pointed out in Lee \& Bang [12]. Other possible causes include steel fatigue due to vibration or being shaken by the wind, failure or incorrect placement of the bolts in the base of the structure or in the joints between the different steel tube sections, as described in Chou \& $\mathrm{Tu}[13]$.

The investigation and study of real failures can provide important information for the improvement of the design of structural elements based on new theories, concepts, construction details, monitoring, etc. [14-16]. The reason for publishing the present study was because only a few papers have been published on the particular case of wind turbine towers. The paper is organized as follows: firstly, the main characteristics of a wind turbine are given, followed by the description of the collapse of one of these structures due to the failure of the tower. The causes of the failure were determined by: visual inspection, laboratory tests, a Finite Element Method (FEM) simulation of the zone in which the failure occurred, and a Design of Experiments (DOE) to assess the influence of the different parameters involved in the 
risk of structural collapse. In the final section, the lessons learnt from the study are given with the aim of contributing to improving the design and construction of wind turbine towers.

\section{Description of the wind turbine}

The Abuela de Santa Ana onshore wind farm is located near the town of Pozo Llorente in the province of Albacete (Spain). It consists of $25 \mathrm{GE}$ Energy 1.5sle Model 1.5KW wind turbines, the diameter of the rotor is $77 \mathrm{~m}$ and the height of the tower varies between $61.4 \mathrm{~m}$ and $85 \mathrm{~m}$. It is operational at the present time under the control of the ACS Company at a nominal power of $37.500 \mathrm{~kW}$. Its geographic coordinates are $39^{\circ} 4^{\prime} 36.5^{\prime \prime}$ latitude and $-1^{\circ} 30^{\prime} 23.5^{\prime \prime}$ longitude. A view of the wind farm with a close-up of a tower can be seen in Fig. 1 .

\section{Fig. 1. General view of the Abuela de Santa Ana wind farm and one of the towers}

The turbine towers are composed of different steel tubes and the flange is fixed to the lower tube and is embedded in the foundations (see Fig.2). The tower tubes are bolted together and are required to maintain the necessary stiffness to support the turbine nacelles fixed to the top of the tower.

The flange is placed in the lower part of the tower. The flange is a steel tube $1.67 \mathrm{~m}$ long and $4.3 \mathrm{~m}$ diameter. It consists of the following components (see Fig. 2):

- Lower T-flange to transmit loads to the foundations.

- Upper flange fixed to the next tower section by M36a bolts.

Fig. 2. Details of the tower/foundation connection. a) Detail of lower flange and foundation; b) Detail of flange and bolts. Source: [17]

The lower tube is totally embedded in concrete except for the upper $0.2 \mathrm{~m}$ which are available for bolting to the tower shell. Due to its failure, the flange in one of the towers between the foundations and the structure was the object of the present study.

\section{Collapse of the turbine tower}

In October 2008, two months after being out into operation, one of the Abuela de Santa Ana wind turbine towers collapsed due to a catastrophic failure in the lower flange fixed to the foundations. An on-site inspection of the damage was made the following day.

Firstly, the joint between the tower and the nacelle was seen to be in good condition with no evidence of damage at this location having caused the failure. Secondly, the steel tube was buckled, as can be seen in Fig. 3. Thirdly, the blades were seen to have damaged the steel tubes during the fall. After the inspection, the most probable cause was therefore identified as the failure of the base of the tower, which was made the focus of future tests to find the definite cause of the collapse.

Fig. 3. View of the tower the day after collapsing

After the base had been analyzed in greater detail, the failure was located in the lower flange. This component had been built from a bar of rectangular cross-section, curved and welded S-355-J2 steel 
according to the UNE-EN-10025-3:2006 code [18] and in the zone of the failure had been welded to a steel tube.

Fig. 4. View of the section in which the failure began

The damaged zone (See Fig.4) showed signs of corrosion, which would later be analyzed to identify the type of failure and its causes. This section was covered with a plastic sheet in order to keep these zones intact and avoid any deterioration in the material due to the weather subsequent to the collapse that could possibly lead to errors in the conclusions of the analysis.

The preliminary visual study identified a sector of approximately $3 \mathrm{~m}$. that had been badly affected by black, blue and brown colored oxidation, in contrast to the rest of the section in which the surface was seen to be clean (Fig.4).

\section{Analysis of the collapse}

\subsection{Visual inspection of the broken section}

A scheme of the flange studied in this work can be seen in Fig. 5. The flange had been positioned in order of the drill holes numbered from 1 to 138 , number 1 being at the centre of the lower tower access door. The broken section to be studied in detail was joined to the flange whose scheme is shown in Fig. 5 .

\section{Fig. 5. Detail of the flange and position of the cracks}

The broken section was found to have started and propagated in the base of the flange neck (see Fig.6a). In photographs taken days after the collapse, various cracks were located in the flange cross-section, as can be seen in Fig. 6:

- The initial crack was located between drill holes 100 and 130 (see Fig.6c)

- Between drill holes 109 and 123 black and blue rust stains were observed (see Fig.6b). These stains were visible in the on-site inspection and were thus assumed to exist before the collapse of the structure.

In view of the above, the start of the break was considered to date approximately from the time when the tower had been constructed, due to the oxidation in the broken section.

The failure mode observed in the flange provided information to make a preliminary diagnosis of the collapse that would later be verified by experimental tests and numerical analysis. This diagnosis identified the initial crack that did not spread any further and that could have been due to the forces induced by the bolt pretension or also possibly by a crack in the flange due to an impact during its installation in the tower.

Fig. 6. Detail of the damaged flange section. a) Side view; b) Top view; c) Detail of crack start point

The detailed analysis of the oxides found in the damaged section included a large amount of blue oxides organized into bands or groups of points (see Fig. 6c and Fig. 7) characteristic of the so-called blue 
brittleness or brittle martensite. The former is often found in most steels and is due to the transformation of austenite into cementite at the grain boundaries when the material is subjected to temperatures around $300^{\circ} \mathrm{C}$. The decomposition of the austenite seriously reduces the toughness of the material. This type of brittleness is accentuated by the segregation of impurities at the grain boundary, which promotes the intergranular breaks typical of brittle fractures [19] and [20]. Some authors have observed that blue brittleness when combined with corrosion cracks can cause disastrous failures in steel components [2123].

\section{Fig. 7. Detail of the broken flange section}

From the initial analysis based on measurements taken on site and a visual inspection, it was considered that the failed flange could have been the determining factor in the collapse of the tower. Details of the flange manufacturing process are given in the following section.

\subsection{Flange manufacturing process}

The flange dimensions are as follows: $4.3 \mathrm{~m}$. external diameter, $0.107 \mathrm{~m}$. maximum thickness, and 0.15 $\mathrm{m}$. in width, with 138 drill holes of $0.039 \mathrm{~m}$. in diameter. The section geometry and tolerances are given in Fig. 8.

Fig. 8. Geometry of flange section

The flange was made from a rectangular section S-355-J2 steel bar (dimensions: $4.3 \times 0.17 \times 0.12$ mxmxm) according to UNE-EN 10025-3:2006 [18]. The first treatment is the normalizing, after which it is cold formed and welded. The next step is the thermal treatment to eliminate any residual stresses after cold-forming. In the final stage it is machined into the required shape within the necessary tolerances. Mechanical properties of this material are well known. Quality tests were done by the steel manufacturer to ensure the material properties of the project requirements.

\section{Experimental tests}

In view of the type of failure discovered in the flange, close to the welded zone, the material was analyzed to obtain the fracture toughness parameters. Three Charpy specimens were extracted from the flange between drill holes 112 and 114, as shown in Fig. 9 [24].

Fig. 9. Detail of the specimen extraction zone. Source [24]

The tests gave mean toughness values of 13 Joules for specimen W (working direction), i.e. in the direction of the tower generatrix (direction of tensile stresses in the flange when the structure is subjected to bending forces), and 10 joules for specimen $\mathrm{M}$ (manufacturing direction), i.e. longitudinal direction of laminated bar from which the flange is formed, as shown in Table 1.

Table 1. Experimental Results 


\begin{tabular}{lccccc}
\hline & Sy (MPa) & $\mathrm{Su}(\mathrm{MPa})$ & $\mathrm{A}(\%)$ & $\begin{array}{c}\mathrm{Kv}\left(+13^{\circ} \mathrm{C}\right) \\
(\mathrm{J})\end{array}$ & $\mathrm{Kv}\left(-20^{\circ} \mathrm{C}\right)(\mathrm{J})$ \\
\hline Flange W $\left(^{*}\right)$ & 422 & 557 & 24 & 62 & 13 \\
Flange M (**) & 383 & 536 & 28 & --- & 10 \\
S355 J2 & $>295$ & $450-600$ & $>18$ & --- & $>27$ \\
\hline
\end{tabular}

(*) W: Working direction

(**) M: Manufacturing direction

Reference values obtained for S355J2 grade with 105 mm width from UNE-EN 10025-2 [25].

Yield strength (Sy), Tensile Strenght (Su), Deformation (A), Toughness (Kv)

Since the value was below the $27 \mathrm{~J}$ given in the EN10025-3 Code [18], it was therefore concluded that the fracture toughness of the material was unsatisfactory in all directions. In view of these results, a serious weakness was identified in the material that could have been responsible for unforeseeable failures in the behavior of the structure. The experimental results show that the material does not possess the properties required by the current code and this anomaly could have caused the abnormal behavior of the structure that had not been considered in its design.

\section{Finite element modelling}

In the present work, a numerical model based on Finite Element Method studied the behavior of the

188 flange in order to analyze the cause of the collapse. The procedure followed in this stage consisting of 189 a detailed geometrical model of a sector of the flange, taking advantage of its symmetry. The upper and lower steel tubes were included, as were the zones affected by welding and the bolts.

FEM makes it possible to calculate strains and stresses and the possible failure modes under a range of stresses and working conditions [26]. Ansys-Workbench R16.1 Academic software [27] and [28] was used for this study.

194 The analyses were supplemented by a design of experiments (DOE) study (see Section 7) in which the influence of the different input variables was assessed to identify the response of the flange under different conditions.

\subsection{Material properties and geometry}

199 The materials were modelled considering the steel's elastic properties with linear behavior until 200 yielding. The defined material was steel with a modulus of elasticity of $200 \mathrm{GPa}$ and a Poisson's 201 Coefficient of 0.3 , yield strength of $250 \mathrm{MPa}$ and ultimate tensile strength of $460 \mathrm{MPa}$. These properties have been taken from the manufacturer datasheet. 
The geometrical model studied consisted of the lower flange, the upper flange and a bolt joining both parts, to which symmetry conditions were applied in order to reduce the computational cost of the models. Details of the model geometry can be seen in Fig. 10.

\section{Fig. 10. Geometric model: a) Lower flange; b) Upper flange and bolt; c) Complete} (symmetry) model.

\subsection{Finite elements used and contact model}

SOLID95 type finite elements were used for the flange and SHELL93 for the steel tube at a distance from the joint (see Fig.11a). These elements are suitable for modelling curved zones and complex geometries, as in the case under study [25-27].

SOLID95 is a 3-D element with 20 nodes and three degrees of freedom able to accurately simulate irregular geometries and structural phenomena such as plasticity, creep and large deformations, among others [29].

SHELL93 is an element defined by 8 nodes and three degrees of freedom in each node (displacement and rotations in three directions of the space) and is suitable for curved plate models such as the steel tube at a distance from the joint in the present study [29].

The mesh size was minimum $0.0013 \mathrm{~m}$ and maximum $0.27 \mathrm{~m}$, with a total of 266.194 nodes and 71.117 elements. As can be seen in Figure 11b, certain zones of the geometry were modelled with a very fine finite elements mesh due to the curves and transitions between the elements.

\section{Fig. 11. Finite elements mesh: a) General view; b) Detail of the mesh in the bolt}

In this case, the average element quality ratio is 0.806 out of 1 . In consequence, numerical results are in good agreement with the expected behavior. For three-dimensional elements, this metric is based on the ratio of the volume to the sum of the square root of the sum of the square of the edge lengths.

The model was completed with the configuration of the contact between elements and the application of boundary conditions, which consisted of frictional contact between the flanges surfaces and bonded contact between the bolt head and the upper flange surfaces and for the nut with the lower flange surfaces (see Fig.12). The friction coefficient considered was 0.1, adopting an Augmented Lagrangian formulation [30].

\section{Fig. 12. Contacts in model}

\subsection{Loads and boundary conditions}

This section provides details of the loads applied to the finite element (FE) model and the boundary conditions considered for the joint as well as the simplification procedure in order to obtain realistic values and structural response from the engineering point of view.

To begin with, use was made of the flange symmetry to simplify the model and represent the actual continuity of the tower shell and flanges. In this way, only a $1 / 138^{\text {th }}$ sector of the flange was simulated and symmetry conditions were applied (see Fig. 13). Secondly, a restriction was applied on the 
$F=\frac{P_{a}}{v}=\frac{C_{p} \cdot P_{d}}{v}$

$P_{a}=C_{p} \cdot P$

$P=\frac{1}{2} \cdot \rho \cdot A \cdot v^{3}$

Where: (C in Fig. 13).

- A pretension load applied on the bolt joining the upper and lower flanges at a value of $519.91 \mathrm{kN}$ (D in Fig. 13).

The force generated by the wind on the blades causes a bending moment at the base of the tower that subjects the joint to tensile and compressive forces. There are several ways to obtain the wind load on the blades [13], [10]. The use of Computer Fluid Dynamics (CFD) is a useful methodology to obtain the wind load on blades including the aeroelastic behavior. Other authors used this methodology in the last years [31]. Furthermore, the influence of the blade material properties on the tower wind load could be taking into account [32]

In the present work, the load is obtained following the standards and guides as follows [33]. This horizontal force is limited by the available power, $P_{a}$. The available power is obtained by applying a correcting ratio to the power generated due to the kinetic energy of the wind, $P$ (see Eq. (1)). The maximum efficient power of a turbine is restricted by the Betz Limit, which is called the "power coefficient", $C_{p}$ [33]. Betz's Law defines this coefficient for any design of wind turbine at 0.59 . Despite the fact that Betz Law establishes the theoretical maximum power efficiency at $59 \%$, other factors such as strength or durability reduce this value to $0.35-0.45$. Usually, for high performance equipment, the Betz limit value considered is 0.4 .

The power generated is determined by the kinetic energy of the wind in accordance with Eq. (2).

$\rho$ : Air density in $\mathrm{kg} / \mathrm{m}^{3}$

$A$ : Area swept by rotor in $\mathrm{m}^{2}$

$v$ : Linear velocity of the wind in $\mathrm{m} / \mathrm{s}$

The horizontal force on the rotor is determined by Eq. (3).

275 Data on the characteristics of the rotor are required for calculating the horizontal force. The 


\begin{tabular}{lc} 
Table $2 . \quad$ Wind turbine information \\
\hline Wind power component & Values \\
\hline Rotor diameter, $D(\mathrm{~m})$ & 77 \\
Swept area, $A\left(\mathrm{~m}^{2}\right)$ & 4656.6 \\
Nacelle weight, $(\mathrm{kg})$ & 50000 \\
Rotor + hub weight $(\mathrm{kg})$ & 31000 \\
Wind Speed, $v(\mathrm{~m} / \mathrm{s})$ & 5.21 \\
\hline
\end{tabular}

The values obtained for the power and for the horizontal force on the rotor are shown in Table 3.

Table 3. Power and load on the wind turbine.

\begin{tabular}{lc} 
Loads & Values \\
\hline Power $(\mathrm{kW})$ & 742.41 \\
Avaliable Power $(\mathrm{kW})$ & 296.96 \\
Wind force $(\mathrm{kN})$ & 46.57 \\
\hline
\end{tabular}

284 The maximum tensile stress on the tower flange is due to two main forces (see Eq. (4)):

285 - The bending moment caused by the horizontal force of the wind on the rotor.

286 - The weight of the turbine unit and the tower, which generate a normal force on the flange.

$287 \quad \sigma_{\max (c)}=\frac{M_{f}}{W_{f}}+\frac{P_{p}}{S}$

288 Where:

$M_{f}$ : Bending moment on the tower flange $(\mathrm{kN} \cdot \mathrm{m})$

$290 W_{f}$ : Bending resistance $\left(\mathrm{m}^{3}\right)$

$291 \quad P_{p}$ : Self-weight $(\mathrm{kN})$

$292 S$ : Cross-section area of the tower $\left(\mathrm{m}^{2}\right)$

293 The bending moment in the tower flange is obtained by multiplying the horizontal force on the rotor by

294 the distance to the base of the tower (Eq. (5)).

$295 \quad M_{f}=F \cdot d \cdot \gamma$

296 Where: 
$298 d$ : Distance to the base of the tower, $80 \mathrm{~m}$.

$\gamma$ : Safety factor, 1.5

300 To calculate the self-weight, the weight of the tower $\left(P_{w-t o w e r}\right)$ and the weight of the turbine unit $\left(P_{w-}\right.$ 301 turbine) comprising the nacelle, rotor and hub must all be taken into consideration (Eq. (6)). Data 302 necessary to obtain $P_{w-t o w e r}$ and $P_{w-t u r b i n e}$ are shown in Table 2.

304 The weight of the tower $\left(P_{\text {w-tower }}\right)$ is $169.67 \mathrm{kN}$, and the weight of the wind turbine $\left(P_{w-t u r b i n e}\right)$ is $810 \mathrm{kN}$, 305 including the nacelle, rotor and hub[34]. Therefore, the self-weight of the wind turbine $\left(P_{p}\right)$ is 979.67 $306 \mathrm{kN}$.

307 By using these data, the maximum stress on the flange can be expressed by Eq. (4), while the minimum 308 stress can be determined by the tensile stress on the flange (Eq. (7)).

$\sigma_{\min (t)}=\frac{M}{W_{f}}-\frac{P_{p}}{S}$

The stress values on the flange are shown in Table 4.

Table 4. Stress values on the flange

\begin{tabular}{|c|c|}
\hline Stress & \\
\hline $\begin{array}{l}\text { Max. Compression Stress } \\
\sigma_{\max (c)}(\mathrm{MPa})\end{array}$ & 16.64 \\
\hline 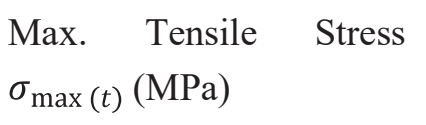 & 9.38 \\
\hline $\begin{array}{l}\text { Max. Compressive load } \\
(\mathrm{kN})\end{array}$ & $(-) 32.57$ \\
\hline Tensile Load $(\mathrm{kN})$ & $(+) 18.37$ \\
\hline
\end{tabular}

313 Based on the results obtained, the normal load applied to the flange was varied between $15 \mathrm{kN}$ of maximum tensile load and $40 \mathrm{kN}$ of maximum compressive load for the study of all the states of intermediate loads between the maximum load (compressive) and the minimum load (tensile).

\section{Fig. 13. Boundary conditions used on a section of the flange}

317 The computational calculation was performed by means of the Newton-Raphson iterative method, 318 based firstly on the pretension analysis of the bolt with a subsequent application of all the loads required 319 by the flange. The pretension load is modelled using a set of pretension elements (element type PRETS179), [28]. This element has one translation degree of freedom, which is the pretension direction. The surfaces connected by the pretension elements must be matched using coincident nodes in both meshes to obtain accurate results. A total of 8 sub-steps and 17 iterations were necessary before model convergence was achieved. 


\subsection{Analysis of the results}

The results obtained from the numerical simulations provided interesting information for an exhaustive analysis of the tower failure. On analyzing the stresses in the joint it was seen that the prestressing of the bolts, before considering the other loads, exerts high forces on the joint, as can be seen in Fig. 14a, since the flange steel's yield strength is exceeded. As a result, the flange is already in a highly stressed state even before the other loads on the structure are taken into account.

After applying loads on the structure, the numerical model showed a high concentration of stresses on the flange neck that coincided with the point of the failure observed in the visual inspection. After analyzing the results of the numerical model, it is shown that the Maximum Von-Mises stress exceeded the material's yield strength (see Fig.14b).

Fig. 14 gives the most important results of the Von Mises stress distribution in the flange. Fig. 14a shows the stress state of the joint when subjected to bolt pretension only. Fig. 14b includes the stress state of the flange when subjected to all the loads.

Fig. 14. FEM model results, equivalent Von-Mises stress. a) applying bolt pretension only (in $M P a$ ); b) for all applied loads (in $M P a$ )

\section{Design of experiments (DOE)}

\subsection{General information}

Design of Experiments (DOE) is a technique used to identify the influence of input parameters on output parameters, as well as to optimize the analysis results. This technique is widely used in engineering to obtain results from a range of input parameters using a minimum of input sampling points. Response surface provide intermediate results. The accuracy of the response surface depends on the type of DOE and the number of cases studied, [35].

In this work, a DOE, type Central Composite Design (CCD), was used to study the influence of certain conditions on the level of stresses in each part of the flange section. This method was used by the authors in previous work on the analysis of structural failures and to optimize new designs [32-34].

In this case, the focus was on the flange bolt pretension, the coefficient of friction in the flange contact, and the vertical force on the flange, which could affect the structural integrity of the joint. The output parameters studied were the maximum stress on the[35] joint and the maximum Von Mises stress in the analysis. Table 5 gives the maximum values adopted for the input variables and their initial values.

Table 5. Values of parameters in the DOE

\begin{tabular}{lccc}
\hline & Minimum Value & Initial Value & Maximum Value \\
\hline Frictional Coefficient & 0.1 & 0.1 & 0.3 \\
Bolt preload (kN) & 100 & 520 & 571 \\
Force (Y axis) (kN) & -40 & 32.5 & 15 \\
\hline
\end{tabular}


The analysis identified the individual critical stress values for each element under different load states. The results obtained allowed us to identify the most important critical points in the joint, the influence of the input variables on each one, and the permitted load limits to keep the structure in a state of stress within the material's admissible limits.

The DOE analysis can identify the cause of the fracture of the joint, the load limits that would cause the collapse of the structure and the different load combinations that would overload the joint and cause it to have brittle behavior.

\subsection{Analysis of the results}

The maximum stress values were the most important results obtained from the numerical analysis of the joint, including the contact stress between both flanges and the individual stress level of both the upper and lower flanges.

In regard to the flange contact pressure (see Fig.15a), the maximum value obtained was in the central axis of the surface and reached a value of $62.8 \mathrm{MPa}$. The maximum Von Mises stress values in upper and lower flanges were very high (see Figs. $15 \mathrm{~b}$ and $15 \mathrm{c}$ ).

Fig. 15. Results of the FE model and DOE analysis: a) Contact stress between upper and lower flanges (in Pa); b) Von Mises stress in upper flange (in Pa); c) Von Mises stress in lower flange (in $\mathrm{Pa}$ )

The DOE results also contributed to the diagnosis of the collapse of the structure by identifying the the most influential variables of the limit stress state of the joint. In the sensitivity analysis shown in Fig. 16 , it can be seen that the most influential parameter is the pretension stress applied to the bolt, followed by the vertical component of the load applied to the steel tube, and lastly the coefficient of friction between the contact surfaces of the flanges.

\section{Fig. 16. Sensitivity analysis}

Fig. 17 shows the response surface that reflects the variation in maximum Von Mises stress in the different parts of the upper and lower flanges. In both cases the maximum Von Mises stress considered was in the part nearest to the steel tube, since, as was seen previously, this is the zone of the flange with the highest concentration of stresses.

The response surfaces obtained from the DOE had maximum values very similar to the upper and lower parts of the flange. It was also seen that the bolt pretension load had a greater influence than the vertical load on the steel tube in the maximum von Mises stress value.

Fig. 17. DOE analysis: External part of the flange (upper and lower part. a) Bolt pretension vs Force Y in upper part of the flange; b) Bolt pretension vs Force Y in lower part of the flange

Fig. 18a shows the influence of the bolt pretension load and of the coefficient of friction with respect to the pressure in the contact between the flanges. It can be seen that the most influential parameter is the pretension load. Figure $18 \mathrm{~b}$ shows the influence of the vertical load on the pressure value; it can be seen that the greatest influence is due to the vertical load applied to the steel tube.

Fig. 18. DOE analysis: maximum pressure in contact between the flanges: a) Contact friction vs Bolt pretension; b) Contact friction vs Force Y. 
Statistical parameters of this DOE are included in Table 6.

\section{Diagnosis}

401

402

403

404

405

406

407

408

409

410

411

412

413

414

415

416

417

418

419

420

421

422

423

424

425

426

427

428

429

430

431

432

433

434

435

436

In the visual inspection carried out on site it was determined that the failure had occurred in two phases in a brief interval of time:

1) The initial failure appeared to be caused by force that disappeared after the crack started (a case of imposed deformation and/or a temporary force derived from an undue event). After this study, it was considered that the failure occurred during the building of the turbine tower, when the pretension was applied to the bolts.

2) The second failure occurred when the tower was in service and the resistant section became weakened because of the initial fracture and progressed until the tower collapsed.

The presence of blue oxides in the fracture zone indicated the possibility of a defect in the manufacture of the element. To verify this, experimental tests were carried out on the toughness of the steel used in the tower and showed that the steel did not meet the requirements of the resilience test. The steel was shown to have very low toughness and was not suitable for use in the structure.

FEM numerical simulations and DOE were used in the present study to analyze the collapse of the wind turbine tower. The results obtained showed that the pretension of the bolts, before considering the remaining forces, exerted considerable stresses on the joint (Fig.14a) that reached the yield strength of the steel in the flange. This high concentration of stresses occurred precisely at the fracture point in the flange neck observed in the visual inspection. The sensitivity analysis by DOE (Fig.16) also showed that the most influential parameter in regard to the von Mises stresses in the joint was the preload stress applied to the bolts. Finally, the response surfaces obtained from the DOE analysis showed that the bolt pretension load had a clearly greater influence than the vertical load and the coefficient of friction in the value of the maximum von Mises stress throughout the range of loads applied to the flange.

Therefore, based on the visual inspection, the laboratory tests carried out and the numerical technique employed (FEM models, sensitivity analysis, response surfaces and the DOE-based method) it can be stated that the collapse of the tower was due to defective material combined with errors in the design of the flange. Both issues make the stress due to the bolt pretension combined with the residual welding stresses are higher than the strength and toughness of the flange material.

\section{Conclusions and lessons learned}

This paper analyze the collapse of a wind turbine tower. The causes of the failure were determined by a visual inspection, laboratory tests, FEM simulations and a subsequent DOE analysis. The main lessons learned can be summed up as follows:

1. On-site inspection of the collapsed structure is essential, together with the immediate isolation of the fractured section to avoid any changes due to oxidation or other agencies.

2. The observation of the fractured section and detailed photographs of all sectors to show differences in colour or appearance can also contribute to clarifying the causes of a collapse. 
3. The experimental analysis of all material properties such as resistance or toughness is fundamental to establish the possible causes of the failure.

4. The creation of detailed FEM models to study the load distribution in the broken section enable the analysis of possible causes of the failure.

5. Applying the DOE technique in the study provides information on the structural behaviour when the physical properties or the loads have wide range of variations and is a fundamental tool for identifying the basic variables involved in the phenomenon.

In the present case, the failure could have been avoided if the material used in the flange had been subjected to the appropriate quality control (toughness test). It could also have been avoided had the flange been better designed to remove the maximum service stress away from the zone affected by the welding, e.g. with a larger chord radius and longer neck.

\section{Acknowledgements}

The authors are grateful for the collaboration of the GICONSIME Research Group at the University of Oviedo and COMONOR Ltd for providing useful information on the tower failure. The authors also acknowledge the partial funding from FEDER funds under the Research Project FC-15-GRUPIN14004. Finally, the authors would also like to thank Swanson Analysis Inc. for the use of ANSYS University Research programs as well as the Workbench simulation environment.

\section{References}

[1] C.C. Chia, J.-R. Lee, Hyung-Joon Bang, Structural health monitoring for a wind turbine system: a review of damage detection methods, Meas. Sci. Technol. 19 (2008) 122001. doi:10.1088/0957-0233/19/12/122001.

[2] Y. Lin, L. Tu, H. Liu, W. Li, Fault analysis of wind turbines in China, Renew. Sustain. Energy Rev. 55 (2016) 482-490. doi:10.1016/j.rser.2015.10.149.

[3] Caithness Windfarm Information Forum (CWIF), Summ. Wind Turbine Accid. Data to 30 Sept. 2014. (n.d.). http://www.caithnesswindfarms.co.uk/ (accessed August 9, 2016).

[4] F.P.G. Marquez, J.M.P. Perez, A.P. Marugan, M. Papaelias, Identification of critical components of wind turbines using FTA over the time, Renew. Energy. 87 (2016) 869-883. doi:10.1016/j.renene.2015.09.038.

[5] L.C.T. Overgaard, E. Lund, Structural collapse of a wind turbine blade. Part B: Progressive interlaminar failure models, Compos. Part A Appl. Sci. Manuf. 41 (2010) 271-283. doi:10.1016/j.compositesa.2009.10.012.

[6] M.M. Shokrieh, R. Rafiee, Simulation of fatigue failure in a full composite wind turbine blade, Compos. Struct. 74 (2006) 332-342. doi:10.1016/j.compstruct.2005.04.027.

[7] C. Kong, J. Bang, Y. Sugiyama, Structural investigation of composite wind turbine blade considering various load cases and fatigue life, Energy. 30 (2005) 2101-2114. doi:10.1016/j.energy.2004.08.016. 
[8] F.M. Jensen, B.G. Falzon, J. Ankersen, H. Stang, Structural testing and numerical simulation of a $34 \mathrm{~m}$ composite wind turbine blade, Compos. Struct. 76 (2006) 52-61. doi:10.1016/j.compstruct.2006.06.008.

[9] L.C.T. Overgaard, E. Lund, O.T. Thomsen, Structural collapse of a wind turbine blade. Part A: Static test and equivalent single layered models, Compos. Part A Appl. Sci. Manuf. 41 (2010) 257-270. doi:10.1016/j.compositesa.2009.10.011.

[10] C.P. Chen, T.Y. Kam, Failure Analysis of Small Composite Sandwich Turbine Blade Subjected to Extreme Wind Load, Procedia Eng. 14 (2011) 1973-1981. doi:10.1016/j.proeng.2011.07.248.

[11] X. Chen, W. Zhao, X.L. Zhao, J.Z. Xu, Preliminary failure investigation of a 52.3m glass/epoxy composite wind turbine blade, Eng. Fail. Anal. 44 (2014) 345-350. doi:10.1016/j.engfailanal.2014.05.024.

[12] K.-S. Lee, H.-J. Bang, A study on the prediction of lateral buckling load for wind turbine tower structures, Int. J. Precis. Eng. Manuf. 13 (2012) 1829-1836. doi:10.1007/s12541-012-0240-y.

[13] J.-S. Chou, W.-T. Tu, Failure analysis and risk management of a collapsed large wind turbine tower, Eng. Fail. Anal. 18 (2011) 295-313. doi:10.1016/j.engfailanal.2010.09.008.

[14] J.M. Adam, F.J. Pallares, Special Issue Learning from Structural failures, Eng. Struct. 32 (2010) 1791. doi:10.1016/j.engstruct.2010.04.026.

[15] N. Delatte, Failure literacy in structural engineering, Eng. Struct. 32 (2010) 1952-1954. doi:10.1016/j.engstruct.2009.12.015.

[16] M. Currie, M. Saafi, C. Tachtatzis, F. Quail, Structural integrity monitoring of onshore wind turbine concrete foundations, Renew. Energy. 83 (2015) 1131-1138. doi:10.1016/j.renene.2015.05.006.

[17] Installing and Assembling Wind Turbine Towers, (n.d.). http://drømstørre.dk/wpcontent/wind/miller/windpower web/en/tour/manu/towrassy.htm (accessed August 9, 2016).

[18] UNE-EN 10025-3. Hot rolled products of structural steels. Part 3: Technical delivery conditions for normalized rolled weldable fine grain structural steels, 2006.

[19] O.F. Higuera Cobos, J.F. Arroyave Londoño, C. Jaramillo I., Estudio de la fragilidad en azul del acero de ultra-alta resistencia assab supra 709., Sci. Tech. ISSN 0122-1701, Vol. 3, №. 40, 2008, Págs. 60-64. 3 (2008) 60-64.

[20] N. Pazos Peinado, Tecnología de los Metales y Procesos de Manufactura, Universida, Caracas, 2006.

[21] W.Y. Chu, Y.B. Wang, L.J. Qiao, Interaction between blue brittleness and stress corrosion cracking, J. Nucl. Mater. 280 (2000) 250-254. doi:10.1016/S0022-3115(00)00065-9.

[22] M.C.S.W. Xue, The blue brittleness of $1 \mathrm{Cr} 17 \mathrm{Ni} 2$ steel submarine motor shaft, Mater. Lett. 57 (2002) 369-373. doi:10.1016/S0167-577X(02)00794-2.

[23] H. Cui, W. Wang, A. Li, M. Li, S. Xu, H. Liu, Failure analysis of the brittle fracture of a thickwalled 20 steel pipe in an ammonia synthesis unit, Eng. Fail. Anal. 17 (2010) 1359-1376. doi:10.1016/j.engfailanal.2010.04.002.

[24] UNE 7475-1:1992. Metallic materials Charpy impact test. Part 1: Test method, 1992.

[25] UNE-EN 10025-2:2006. Hot rolled products of structural steels - Part 2: Technical delivery conditions for non-alloy structural steels., 2006. 
[26] O.C. Zeinkiewick, C. Y.K., The finite element method in structural and continuum mechanics, McGraw Hill, London, 1967.

[27] M. E., G. I., The Finite Element Method and Applications in Engineering using ANSYS, Springer, Berlin, 2005.

[28] S. Moaveni, Finite Element Analysi: Theory and Application with ANSYS, Prentice-Hall, New York, 2007.

[29] S.A. System, ANSYS. User's manual: procedures, commands and elements., Canonsburg, PA, 2005.

[30] J.C. Simo, T.A. Laursen, An augmented lagrangian treatment of contact problems involving friction, Comput. Struct. 42 (1992) 97-116. doi:10.1016/0045-7949(92)90540-G.

[31] R. Rafiee, M. Tahani, M. Moradi, Simulation of aeroelastic behavior in a composite wind turbine blade, J. Wind Eng. Ind. Aerodyn. 151 (2016) 60-69. doi:10.1016/J.JWEIA.2016.01.010.

[32] R. Rafiee, M. Moradi, M. Khanpour, The influence of material properties on the aeroelastic behavior of a composite wind turbine blade, J. Renew. Sustain. Energy. 8 (2016) 063305. doi:10.1063/1.4968600.

[33] The Royal Academy of Engineering, Wind Turbine Power Calculations RWE npower renewables Mechanical and Electrical Engineering, R. Acad. Eng. (n.d.).

[34] thewindpower.net, (n.d.). http://www.thewindpower.net/turbine_es_57_ge-energy_1.5sle.php (accessed December 6, 2016).

[35] D. c. Montgomery, Design and Analysis of Experiments, 5th ed., 2001.

[36] J.J. del Coz Díaz, P.J. García Nieto, A. Lozano Martínez-Luengas, J.L. Suárez Sierra, A study of the collapse of a WWII communications antenna using numerical simulations based on design of experiments by FEM, Eng. Struct. 32 (2010) 1792-1800. doi:10.1016/j.engstruct.2009.09.011.

[37] J.J. del Coz Díaz, F.P. Álvarez Rabanal, P.J. García Nieto, J. Roces-García, A. AlonsoEstébanez, Nonlinear buckling and failure analysis of a self-weighted metallic roof with and without skylights by FEM, Eng. Fail. Anal. 26 (2012) 65-80. doi:10.1016/j.engfailanal.2012.07.019.

[38] J. José del Coz Díaz, J.M. Adam, A.L. Martínez-Luengas, F.P. Alvarez Rabanal, Collapse of a Masonry Wall in an Industrial Building: Diagnosis by Numerical Modeling, J. Perform. Constr. Facil. 27 (2013) 65-76. doi:10.1061/(ASCE)CF.1943-5509.0000310. 

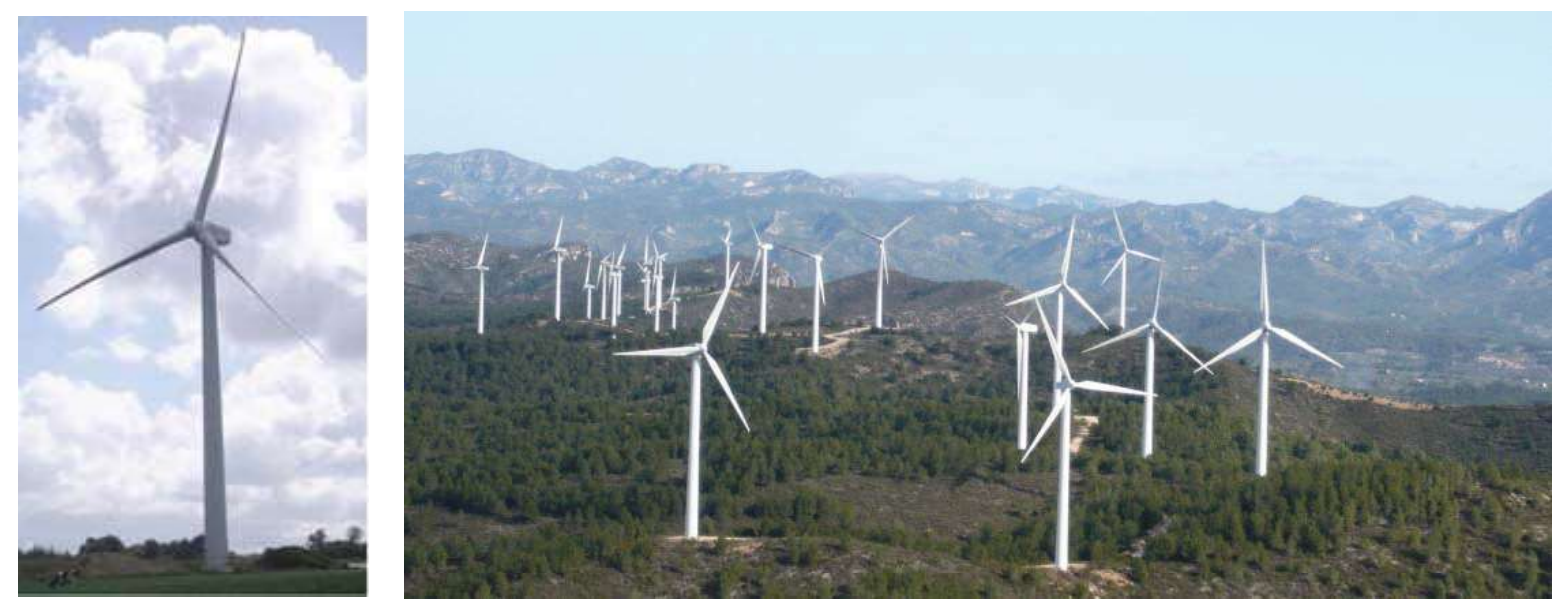

Fig. 1. General view of the Abuela de Santa Ana wind farm and one of the towers 


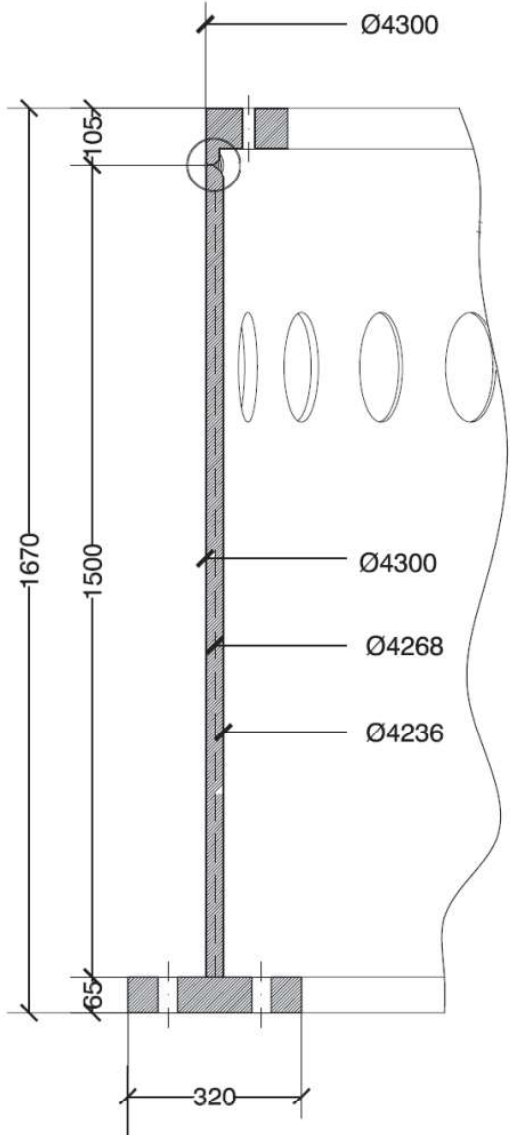

(a)

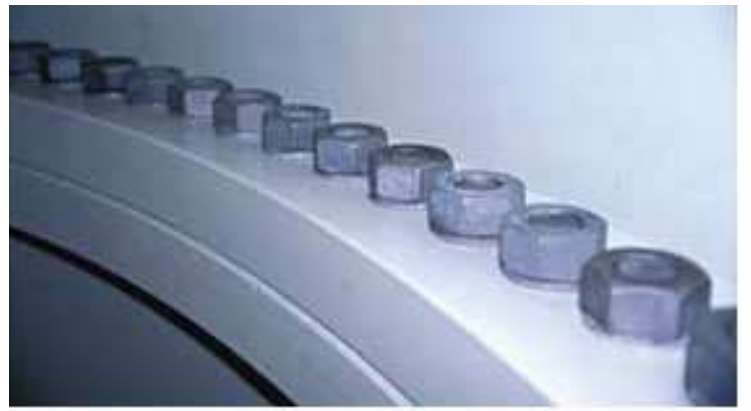

(b)

Fig. 2. Details of the tower/foundation connection. a) Detail of lower flange and foundation; b) Detail of flange and bolts. Source: [16] 


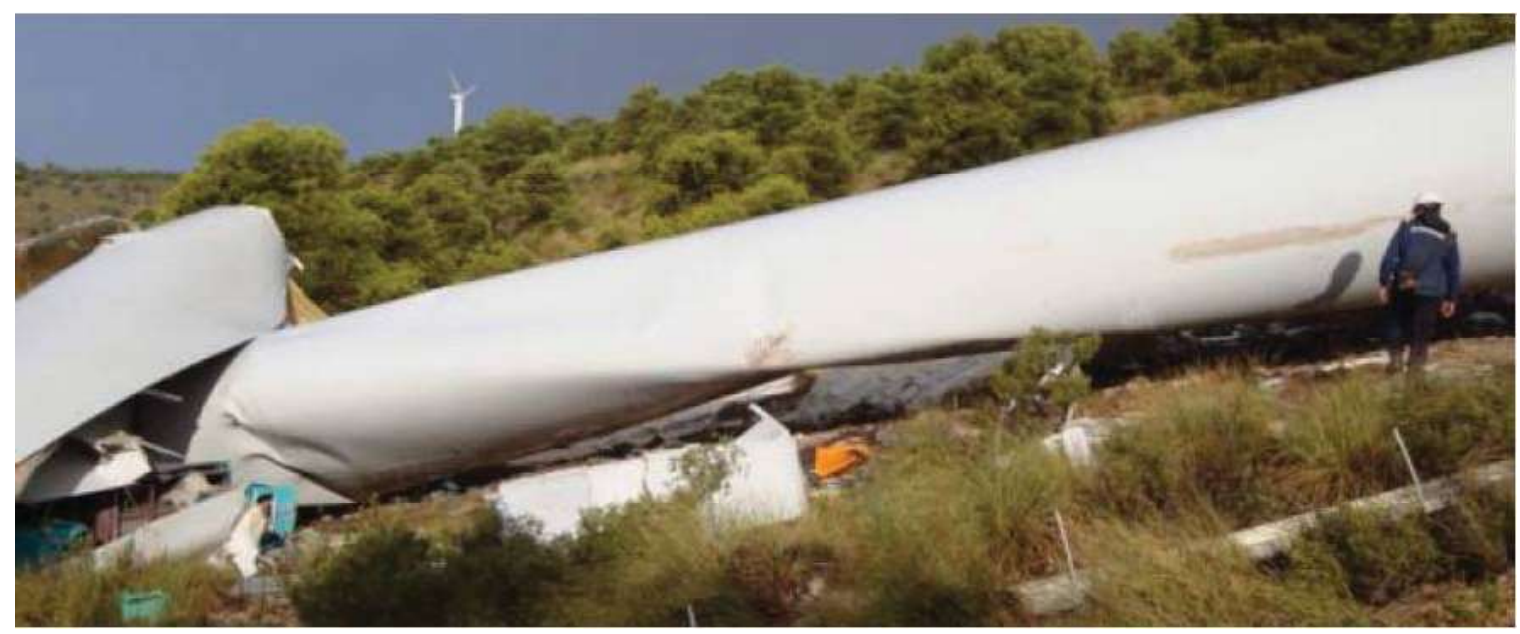

Fig. 3. View of the tower the day after collapsing 


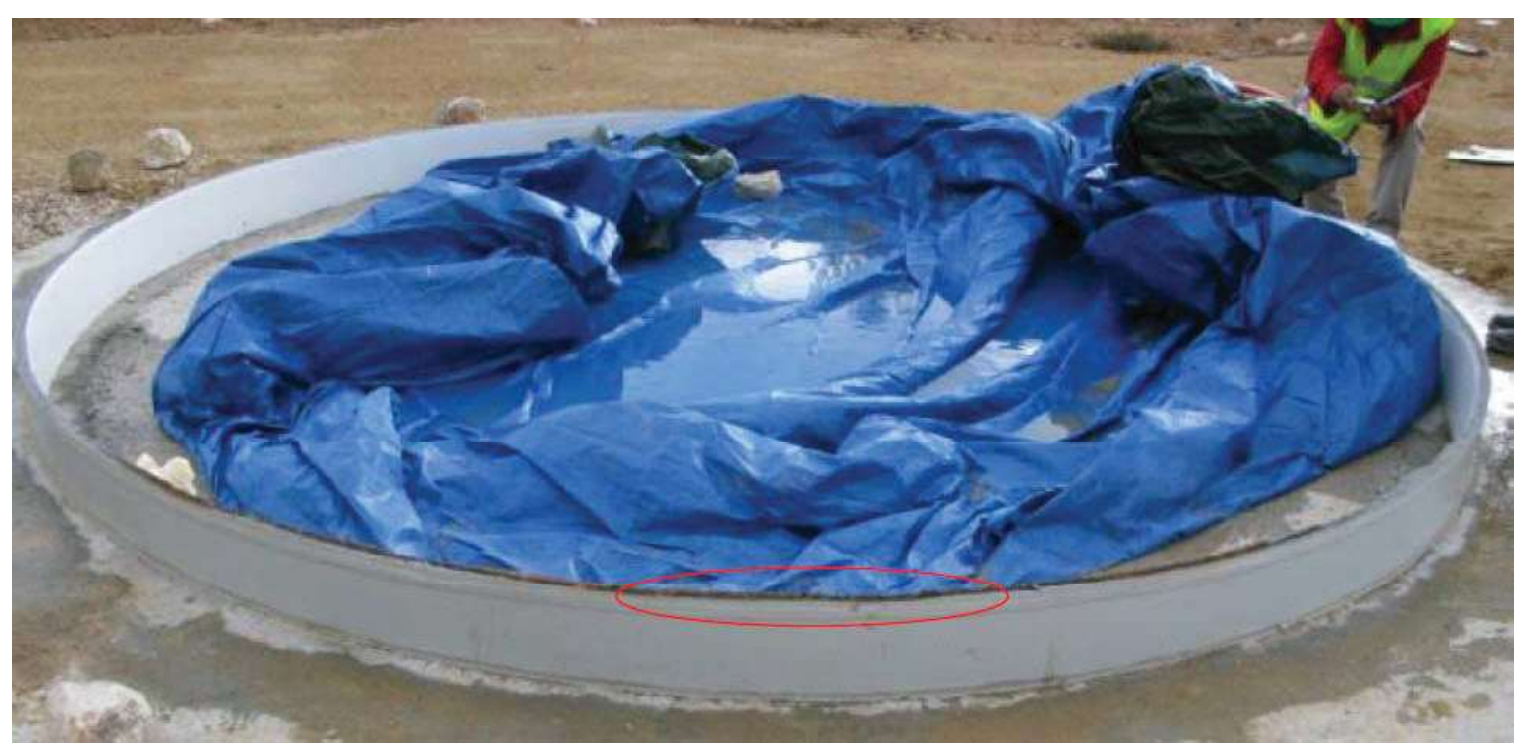

Fig. 4. View of the section in which the failure began 


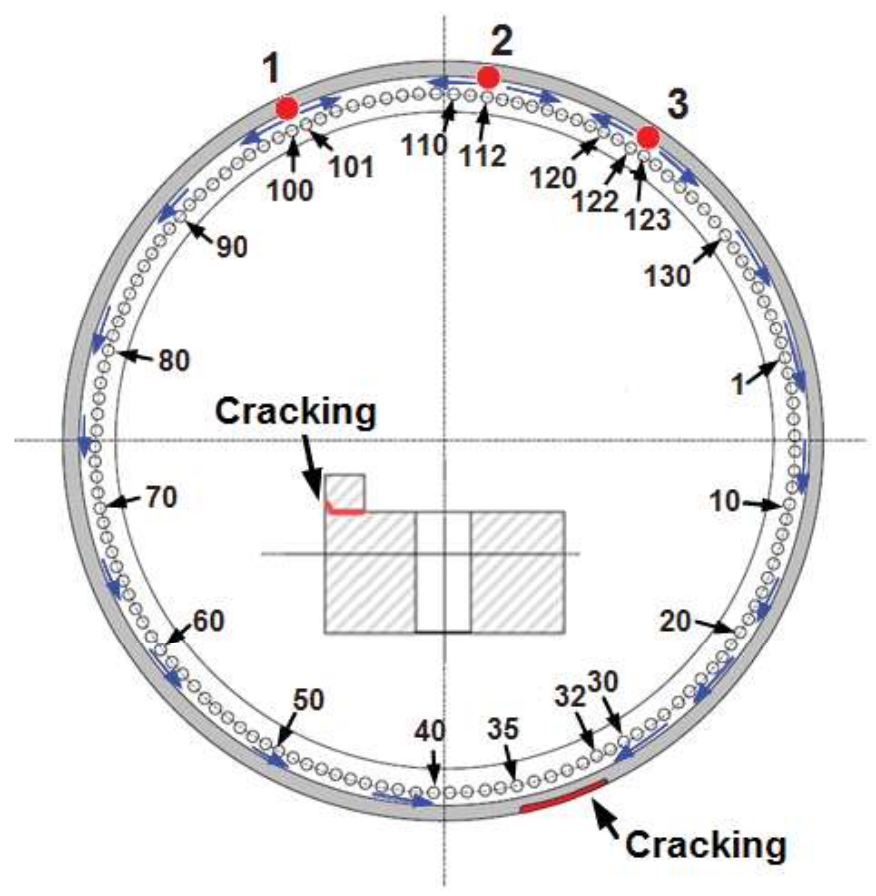

Fig. 5. Detail of the flange and position of the cracks 


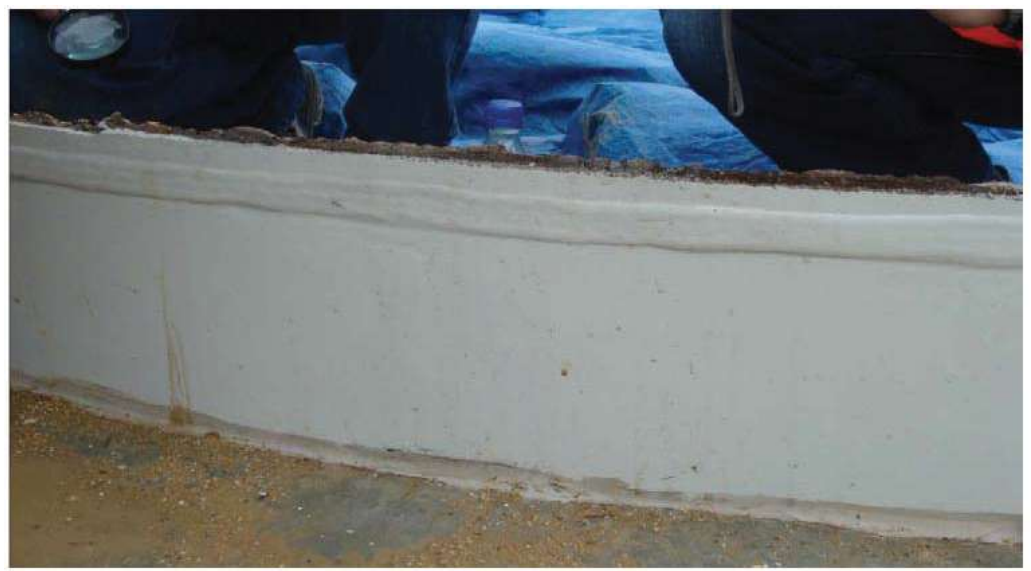

(a)

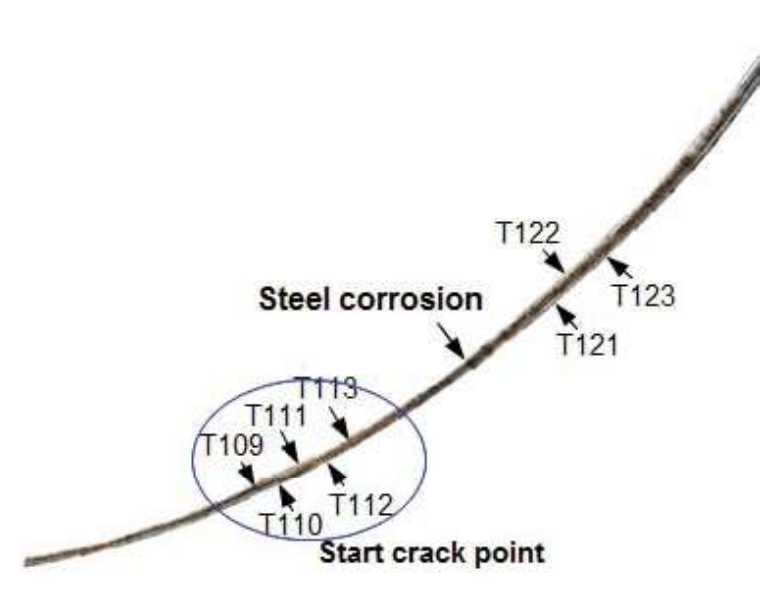

(b)

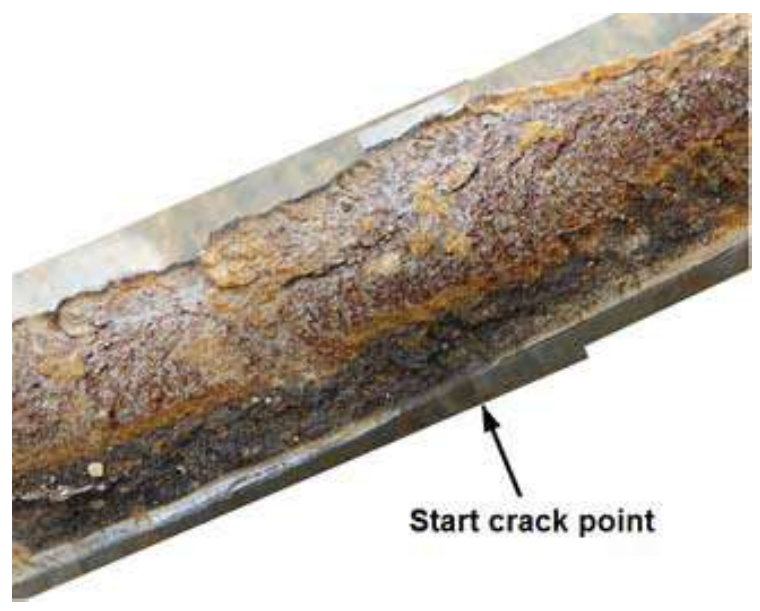

(c)

Fig. 6. Detail of the damaged flange section. a) Side view; b) Top view; c) Detail of crack start point 

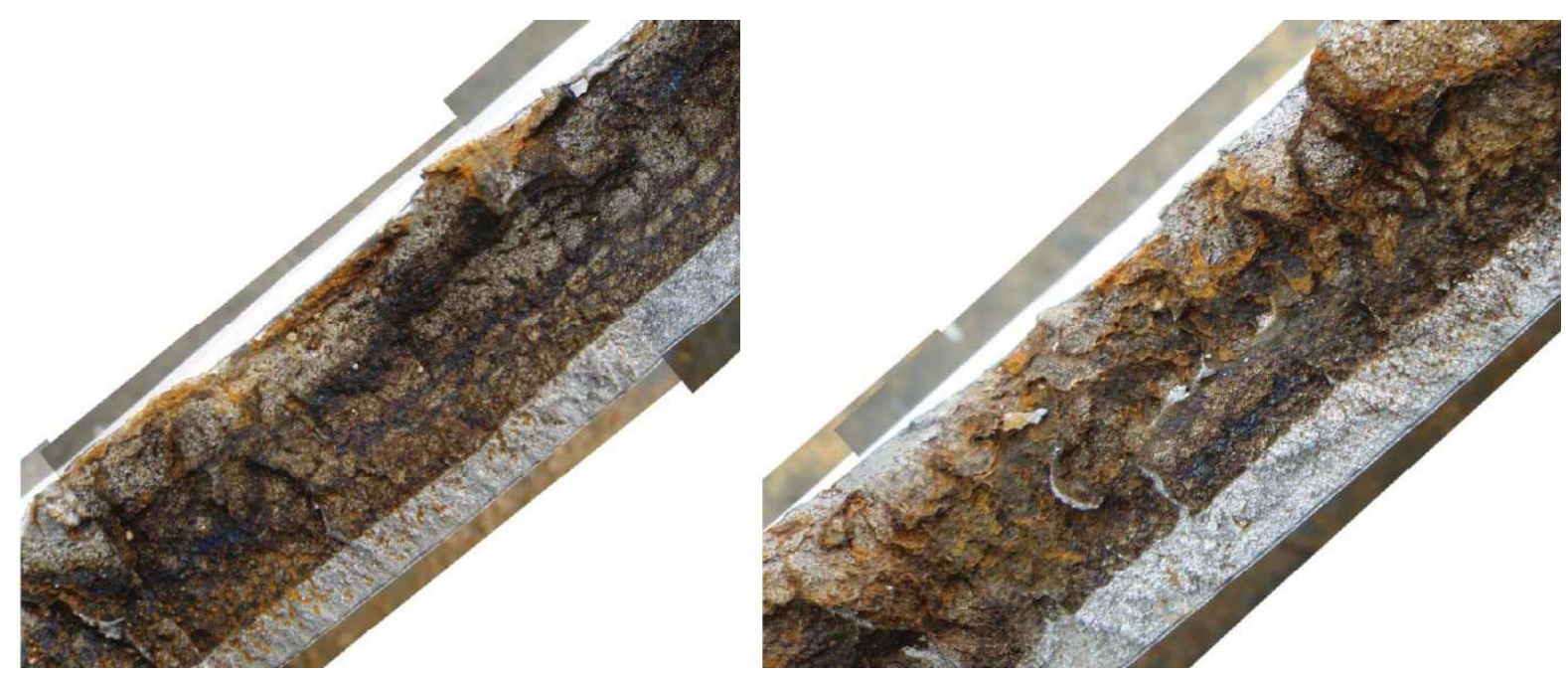

Fig. 7. Detail of the broken flange section 


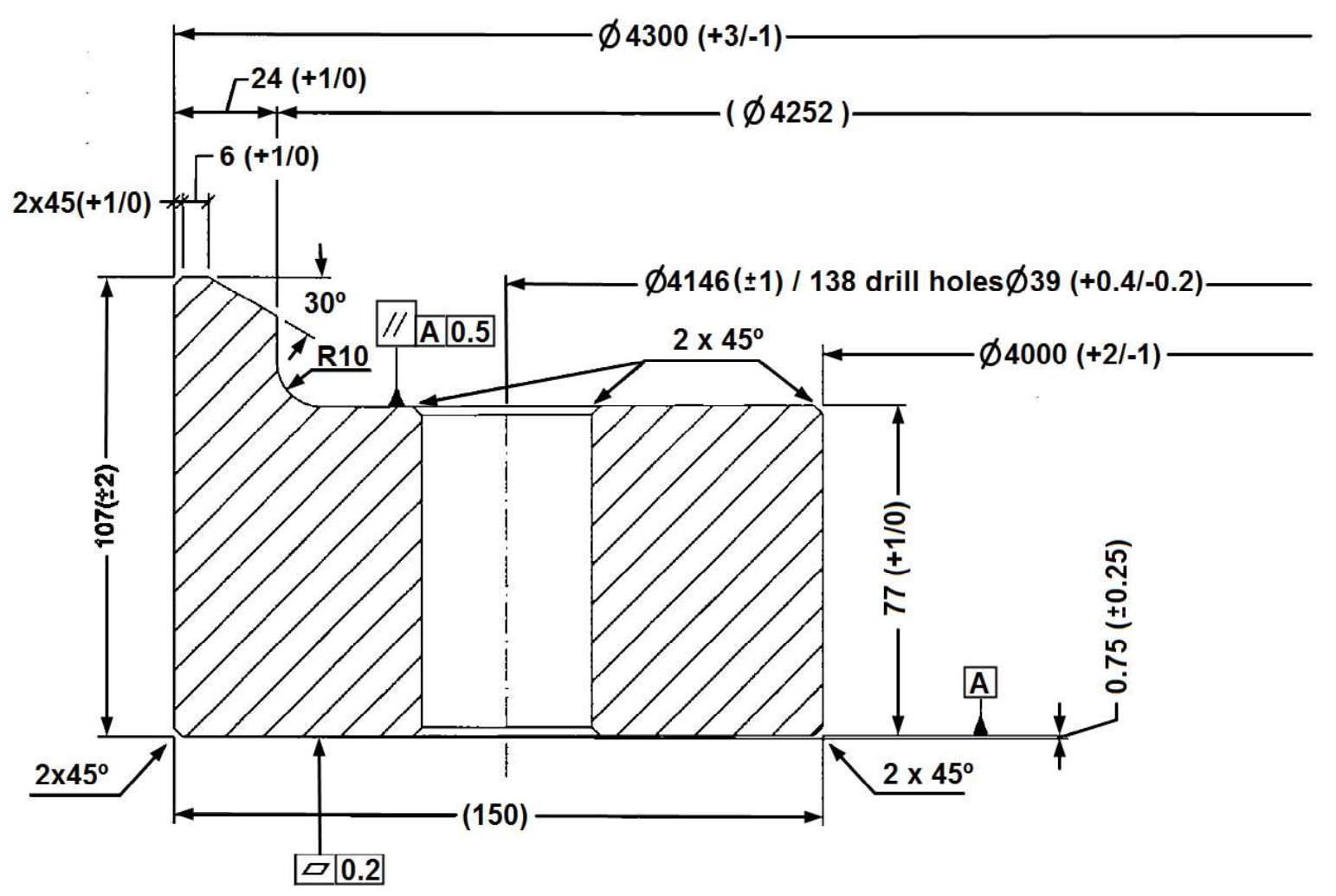

Fig. 8. Geometry of flange section 


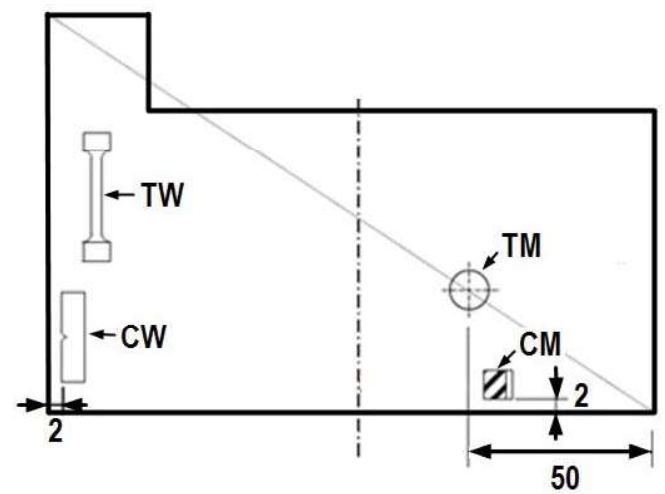

TW: Tensile specimen in working direction CW: Charpy impact test specimen in working direction

TM: Tensile specimen in manufacturing direction

CM: Charpy impact test specimen in manufacturing direction

Fig. 9. Detail of the specimen extraction zone [23] 


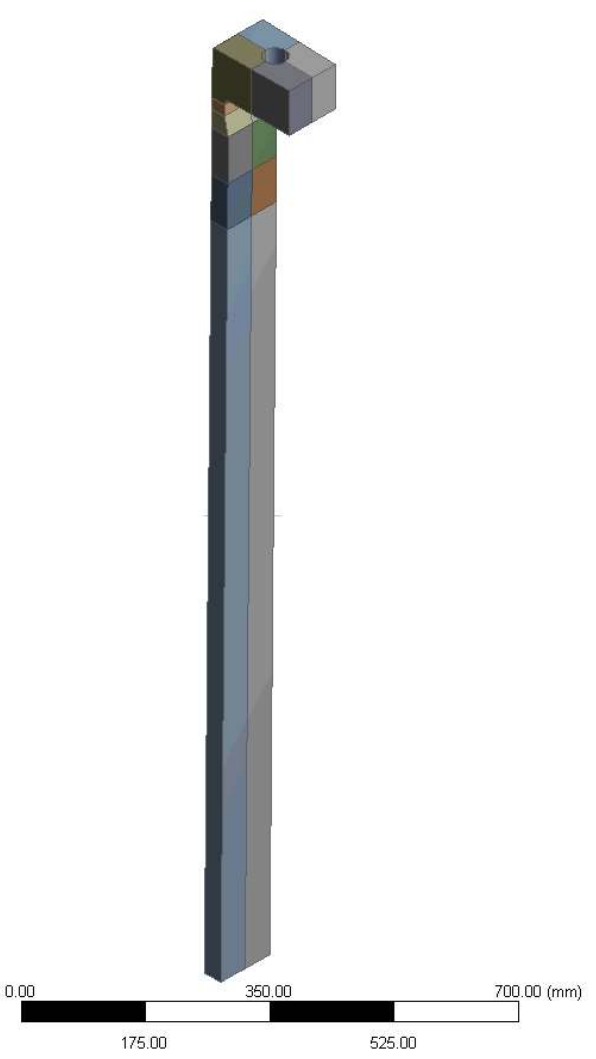

(a)

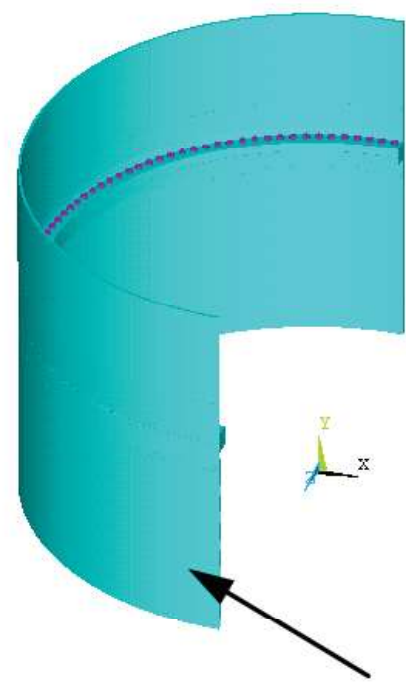

\section{S-355-J2 steel}

(c)
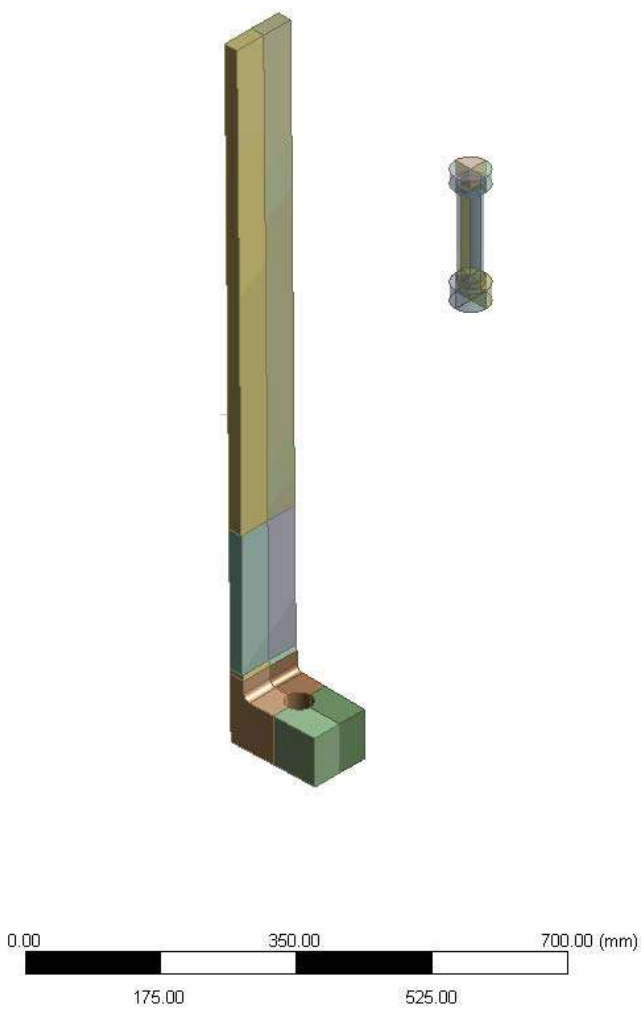

(b)

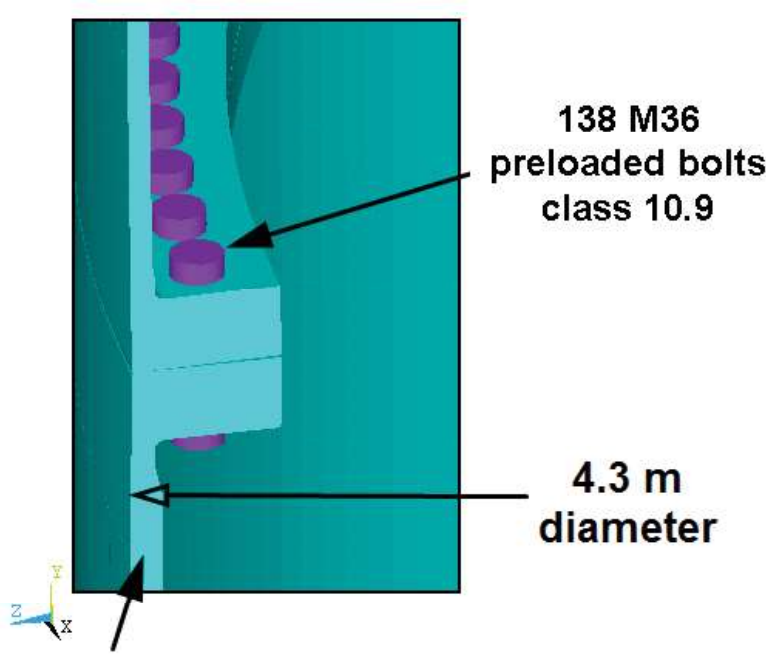

diameter

b) Upper flange and bolt; c) Complete (symmetry) model. 


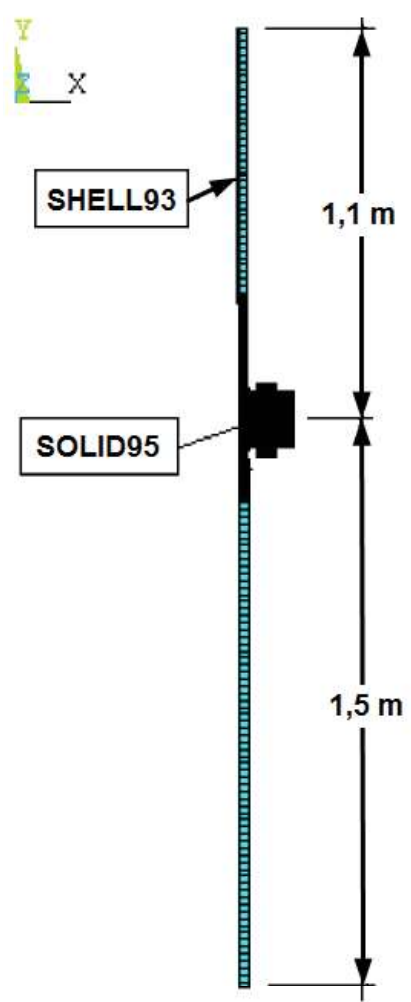

(a)

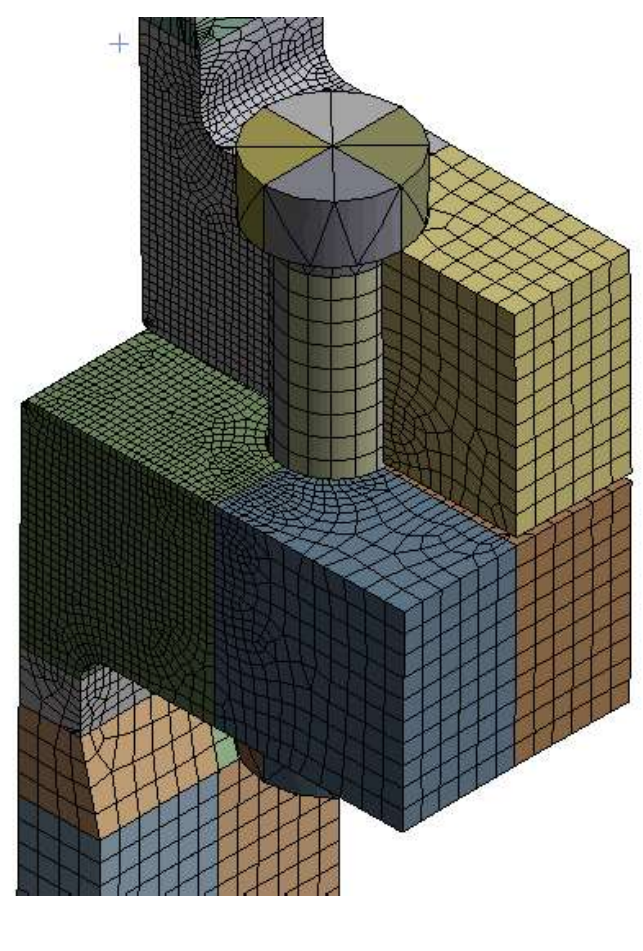

(b)

Fig. 11. Finite elements mesh: a) General view; b) Detail of the mesh in the bolt 


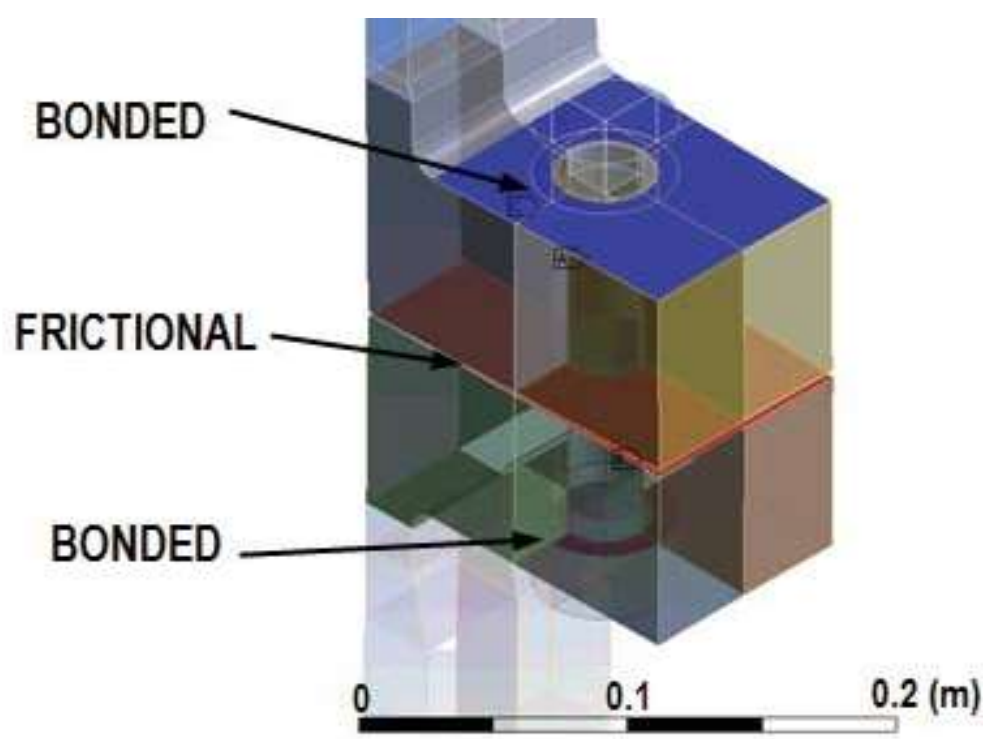

Fig. 12. Contacts in model 
B Force: $32,568 \mathrm{kN}$

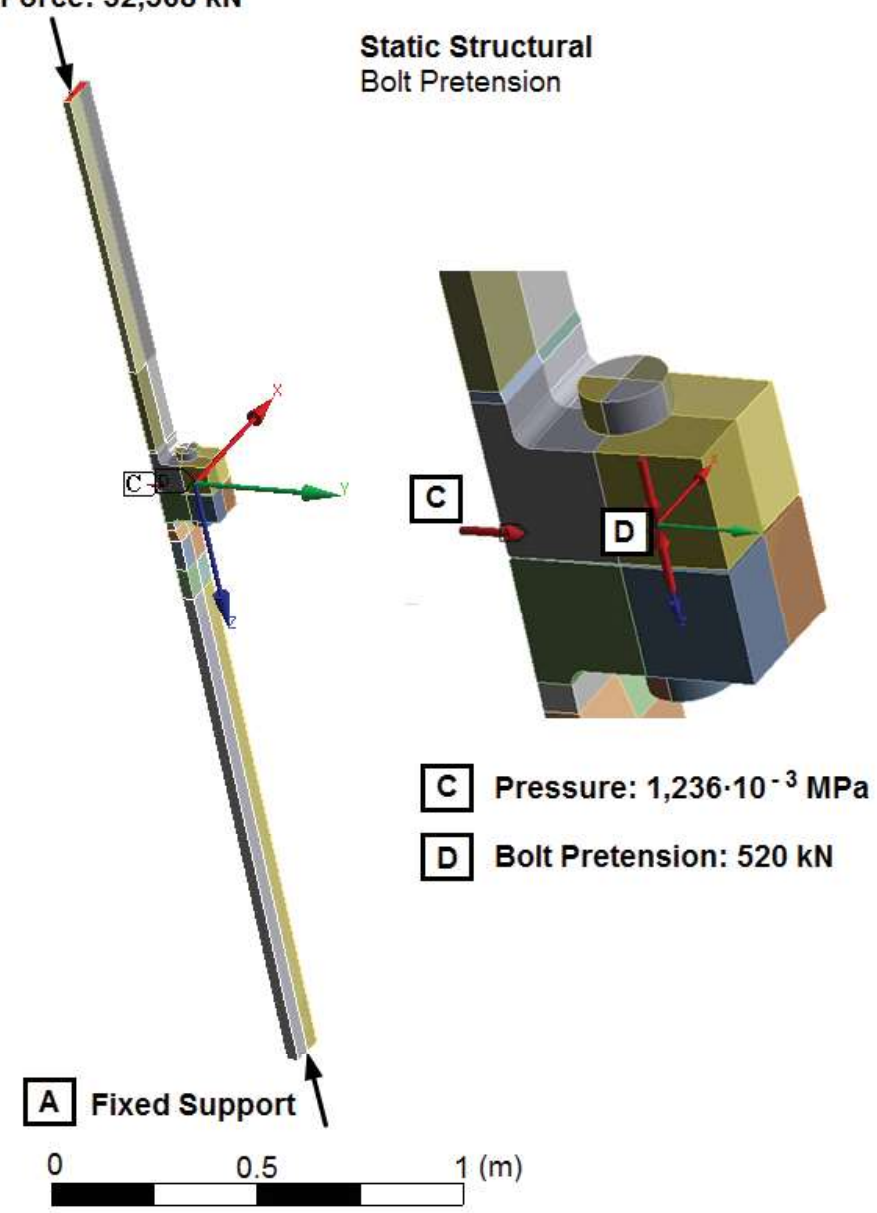

Fig. 13. Boundary conditions used on a section of the flange 


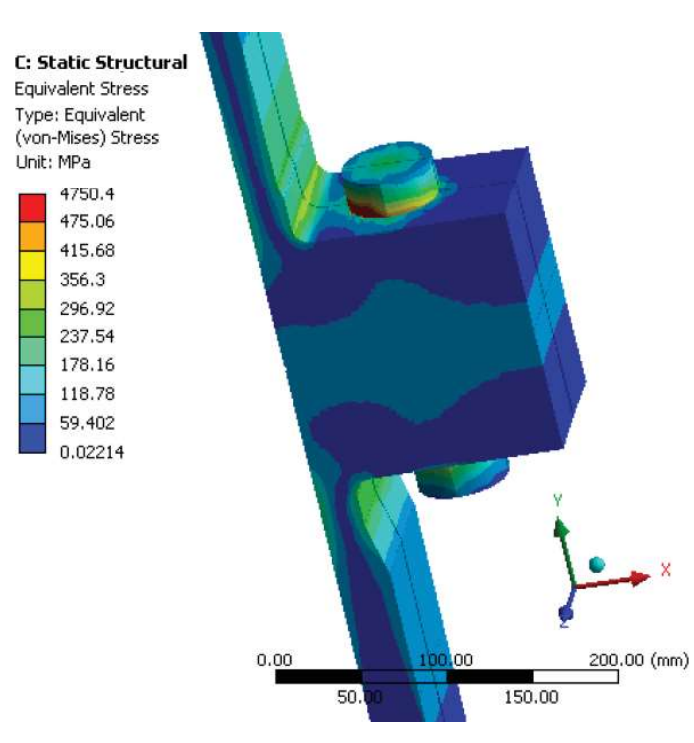

a)

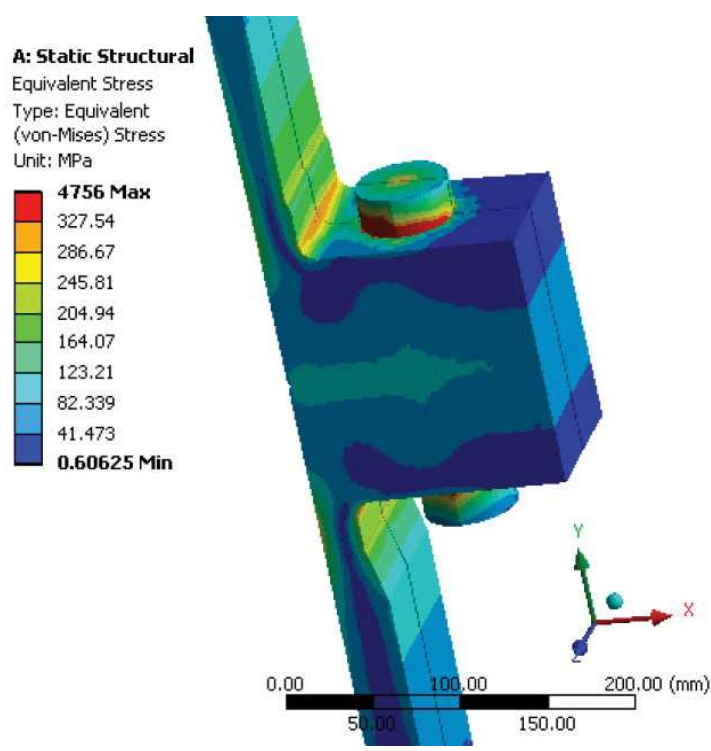

b)

Fig. 14. FEM model results, equivalent Von-Mises stress. a) applying bolt pretension only (in $\mathrm{Pa}$ ); b) for all applied loads (in Pa) 


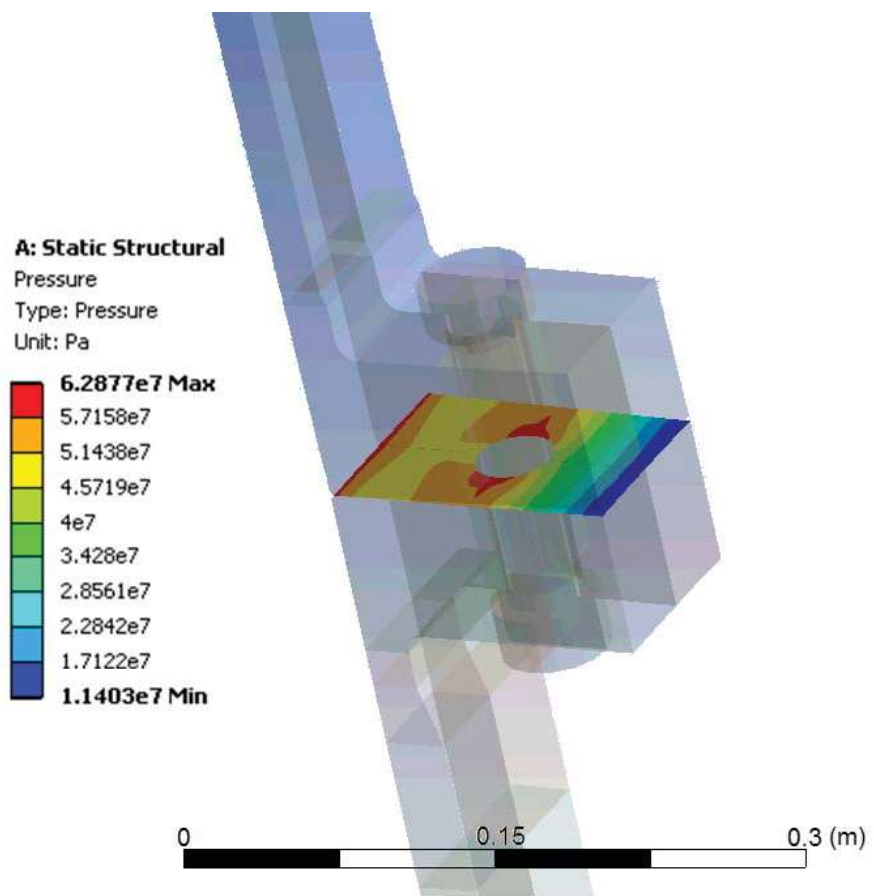

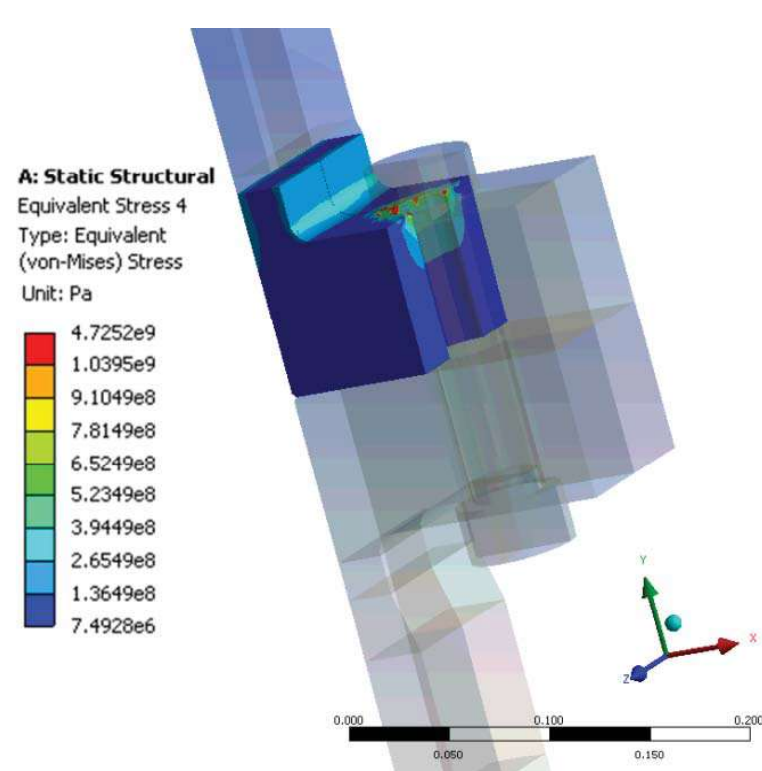

(b)

(a)

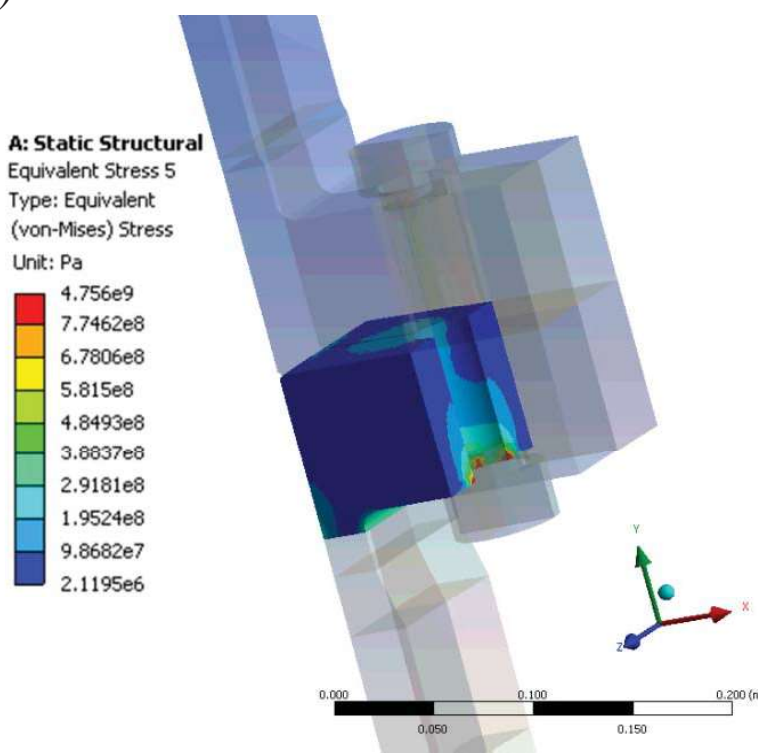

(c)

Fig. 15. Results of the FE model and DOE analysis: a) Contact stress between upper and lower flanges (in Pa); b) Von Mises stress in upper flange (in Pa); c) Von Mises stress in lower flange (in $\mathrm{Pa}$ ) 


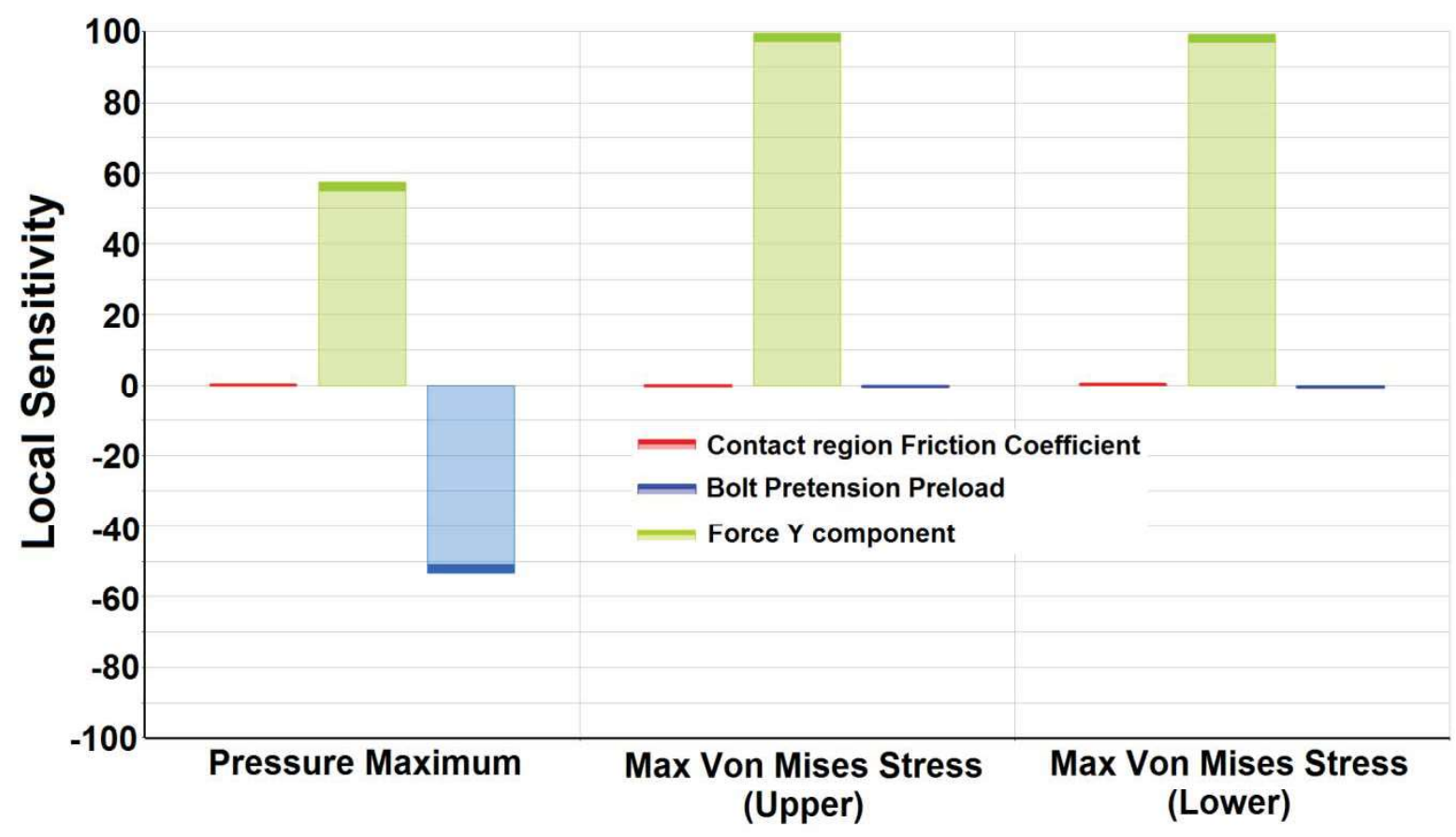

Fig. 16. Sensitivity analysis 


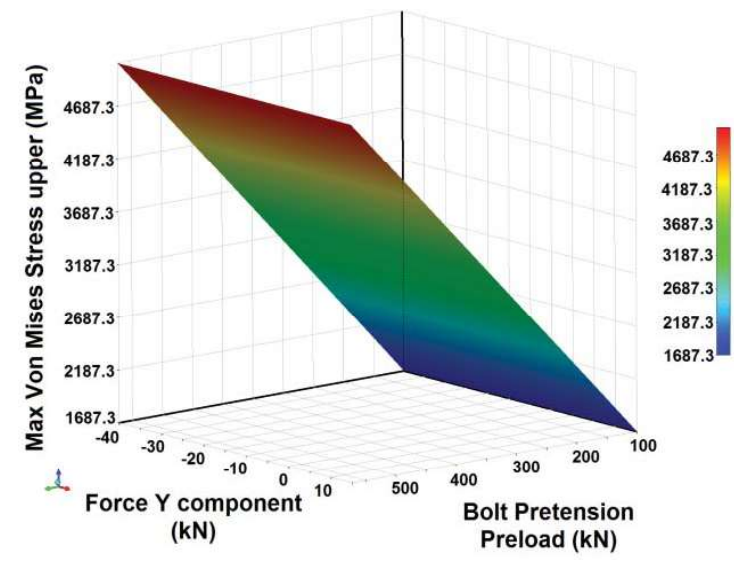

a)

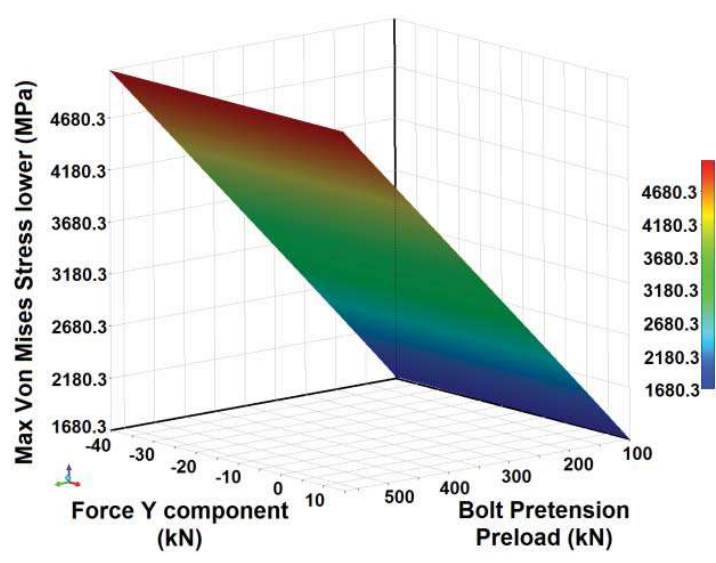

b)

Fig. 17. DOE analysis: External part of the flange (upper and lower part. a) Bolt pretension vs Force $Y$ in upper part of the flange; b) Bolt pretension vs Force $Y$ in lower part of the flange 


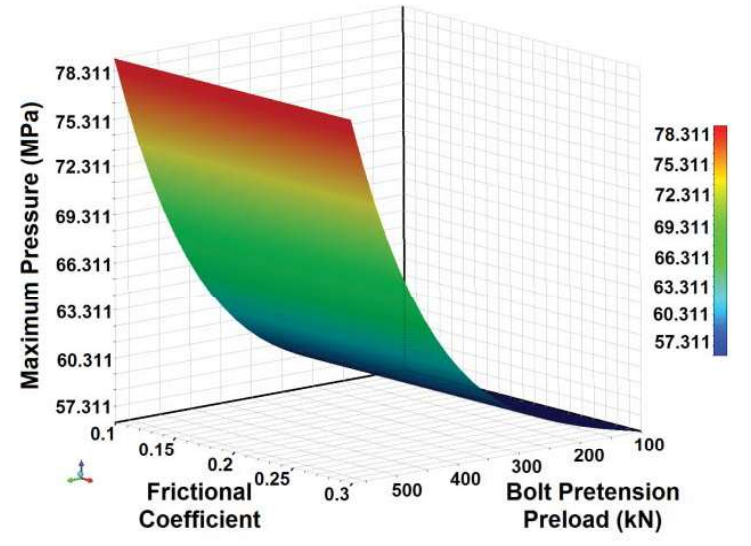

a)

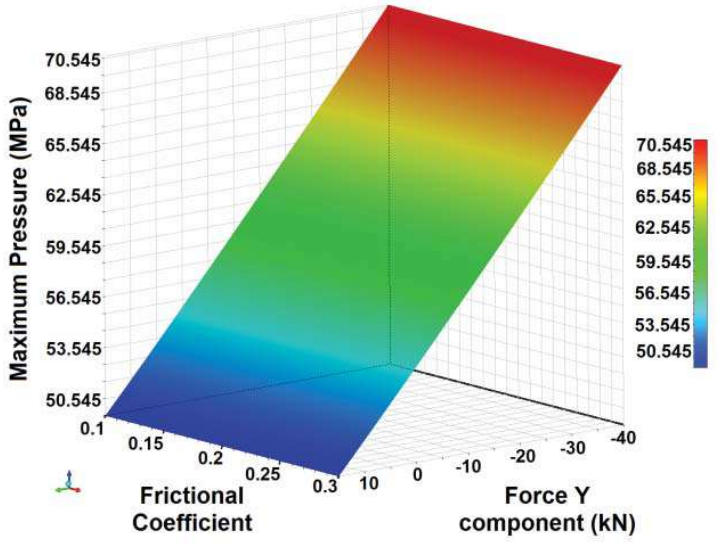

b)

Fig. 18. DOE analysis: maximum pressure in contact between the flanges: a) Contact friction vs Bolt pretension; $b$ ) Contact friction vs Force $Y$. 
Table 1. Experimental Results

\begin{tabular}{lccccc}
\hline & Sy (MPa) & Su (MPa) & A (\%) & $\begin{array}{c}\mathrm{Kv}\left(+13^{\circ} \mathrm{C}\right) \\
(\mathrm{J})\end{array}$ & $\mathrm{Kv}\left(-20^{\circ} \mathrm{C}\right)(\mathrm{J})$ \\
\hline Flange W $\left(^{*}\right)$ & 422 & 557 & 24 & 62 & 13 \\
Flange M $\left(^{* *}\right)$ & 383 & 536 & 28 & -- & 10 \\
S355 J2 & $>295$ & $450-600$ & $>18$ & -- & $>27$ \\
\hline
\end{tabular}

(*) W: Working direction

(**) M: Manufacturing direction

Reference values obtained for S355J2 grade with 105 mm width from UNE-EN 10025-2 [24].

Yield strength (Sy), Tensile Strenght (Su), Deformation (A), Toughness (Kv) 
Table 2. Wind turbine information

\begin{tabular}{lc} 
Wind power component & Values \\
\hline Rotor diameter, $D(\mathrm{~m})$ & 77 \\
Swept area, $A\left(\mathrm{~m}^{2}\right)$ & 4656.6 \\
Nacelle weight, $(\mathrm{kg})$ & 50000 \\
Rotor + hub weight $(\mathrm{kg})$ & 31000 \\
Wind Speed, $v(\mathrm{~m} / \mathrm{s})$ & 5.21 \\
\hline
\end{tabular}


Table 3. Power and load on the wind turbine.

\begin{tabular}{lc} 
Loads & Values \\
\hline Power $(\mathrm{kW})$ & 742.41 \\
Avaliable Power $(\mathrm{kW})$ & 296.96 \\
Wind force $(\mathrm{kN})$ & 46.57 \\
\hline
\end{tabular}


Table 4. Stress values on the flange

\begin{tabular}{lc} 
Stress & \\
\hline $\begin{array}{l}\text { Max. Compression Stress } \\
\sigma_{\max (c)}(\mathrm{MPa})\end{array}$ & 16.64 \\
$\begin{array}{l}\text { Max. Tensile Stress } \\
\sigma_{\max (t)}(\mathrm{MPa})\end{array}$ & 9.38 \\
$\begin{array}{l}\text { Max. Compressive load } \\
(\mathrm{kN})\end{array}$ & $(-) 32.57$ \\
Tensile Load $(\mathrm{kN})$ & $(+) 18.37$ \\
\hline
\end{tabular}


Table 5. Values of parameters in the DOE

\begin{tabular}{lccc}
\hline & Minimum Value & Initial Value & Maximum Value \\
\hline Frictional Coefficient & 0.1 & 0.1 & 0.3 \\
Bolt preload $(\mathrm{kN})$ & 100 & 520 & 571 \\
Force (Y axis) $(\mathrm{kN})$ & -40 & 32.5 & 15 \\
\hline
\end{tabular}


Table 6. Statistical parameters in the DOE analysis.

\begin{tabular}{|c|c|c|c|c|c|c|c|c|}
\hline & $\begin{array}{l}\text { P3 - } \\
\text { Pressure } \\
\text { Maximu } \\
\text { m }\end{array}$ & $\begin{array}{l}\text { P4 - } \\
\text { sint_b_ } \\
\text { sup_ex } \\
t \\
\text { Maxim } \\
\text { um }\end{array}$ & $\begin{array}{l}\text { P5 - } \\
\text { sint_b_ } \\
\text { inf_ext } \\
\text { Maxim } \\
\text { um }\end{array}$ & $\begin{array}{l}\text { P6 - } \\
\text { sint_b_ } \\
\text { sup_tra } \\
\text { nsition } \\
\text { Maxim } \\
\text { um }\end{array}$ & $\begin{array}{l}\text { P7 - } \\
\text { sint_b_ } \\
\text { inf_tra } \\
\text { nsition } \\
\text { Maxim } \\
\text { um }\end{array}$ & $\begin{array}{l}\text { P8 - } \\
\text { sint_b_ } \\
\text { sup_int } \\
\text { Maxim } \\
\text { um }\end{array}$ & $\begin{array}{l}\text { P9 - } \\
\text { sint_b_ } \\
\text { inf_int } \\
\text { Maxim } \\
\text { um }\end{array}$ & $\begin{array}{l}\mathrm{P} 10 \\
\text { Stress } \\
\text { Intensit } \\
\text { y } 2 \\
\text { Maxim } \\
\text { um }\end{array}$ \\
\hline $\begin{array}{l}\text { Coefficient of } \\
\text { Determination } \\
(\text { Best Value }=1)\end{array}$ & & & & & & & & \\
\hline Learning Points & 0.9945 & 0.9993 & 0.9990 & 0.9999 & 0.9997 & 0.9999 & 0.9999 & 0.9999 \\
\hline $\begin{array}{l}\text { Relative } \\
\text { Maximum } \\
\text { Absolute Error } \\
\text { (Best Value = 0\%) }\end{array}$ & & & & & & & & \\
\hline Learning Points & 19.1818 & 5.8119 & 8.4279 & 0.4350 & 3.2576 & 0.8412 & 1.7775 & 0.6130 \\
\hline $\begin{array}{l}\text { Relative Average } \\
\text { Absolute Error } \\
\text { (Best Value }=0 \% \text { ) }\end{array}$ & & & & & & & & \\
\hline Learning Points & 5.326735 & 1.9106 & 2.0452 & 0.1387 & 1.1117 & 0.3627 & 0.6299 & 0.2586 \\
\hline
\end{tabular}

